\title{
Activists, raiders, and directors: \\ Opportunism and the balance of corporate power
}

\author{
Thomas H. Noe \\ Saïd Business School and Balliol College \\ University of Oxford \\ Michael J. Rebello \\ School of Management \\ University of Texas at Dallas \\ Ramana Sonti \\ Indian School of Business
}

This version: November 2007

\begin{abstract}
We model corporate governance in a world with competitive securities markets as well as markets for corporate assets. We show that varying the liquidity and opacity of corporate assets, the vitality of the market for corporate control, and the costs of enforcing shareholder rights to cash flows leads to a plethora of institutional designs. When asset liquidity is high, shareholder rights are enforced through the option to liquidate as in a mutual fund. When the opacity of corporate assets is relatively high and asset liquidity is relatively low, firms will eschew reliance on board monitoring and instead rely on shareholder activism. An increase in the cost of ownership concentration, by increasing the inefficiency of shareholder activism, will increase the reliance on board activism and decrease the reliance on CEO compensation. Decreases in the cost of enforcement of shareholder rights and the opacity of corporate assets, and increased raider activity further strengthen the preference for activist boards.
\end{abstract}

JEL Classification Codes: G20, G34;

Keywords: governance, asset liquidity, institutional design 


\title{
Activists, raiders, and directors: \\ Opportunism and the balance of corporate power
}

This version: November 2007

\begin{abstract}
We model corporate governance in a world with competitive securities markets as well as markets for corporate assets. We show that varying the liquidity and opacity of corporate assets, the vitality of the market for corporate control, and the costs of enforcing shareholder rights to cash flows leads to a plethora of institutional designs. When asset liquidity is high, shareholder rights are enforced through the option to liquidate as in a mutual fund. When the opacity of corporate assets is relatively high and asset liquidity is relatively low, firms will eschew reliance on board monitoring and instead rely on shareholder activism. An increase in the cost of ownership concentration, by increasing the inefficiency of shareholder activism, will increase the reliance on board activism and decrease the reliance on CEO compensation. Decreases in the cost of enforcement of shareholder rights and the opacity of corporate assets, and increased raider activity further strengthen the preference for activist boards.
\end{abstract}

JEL Classification Codes: G20, G34;

Keywords: governance, asset liquidity, institutional design 


\section{Introduction}

Regulators and governments around the world are rewriting the rules of corporate governance. Most of these reform efforts focus on increasing board vigilance and independence. In the United States, this reforming force propelled the passage of the Sarbanes-Oxley act; in the European Union (E.U.), it is marshaling behind an E.U. code of corporate governance. ${ }^{1}$

While some academic research supports the hypothesis that shareholder rights and board vigilance stimulate the growth of both economies and financial markets [for instance, see ?)], this hypothesis cannot rationalize some fairly important features of actual financial market development. For example, the flowering of diversified public equity ownership in the U.K, on soil "poisoned" by the Foss vs. Harbottle decision (1843) (which stripped minority shareholders of virtually all legal protection) seems difficult to square with the essential importance of shareholder rights [see ?)]. Moreover, researchers [e.g., ?)] as well as legislators have argued that shareholder rights can be used by activist shareholders to pursue private gains or personal political agendas at the expense of overall shareholder welfare. ${ }^{2}$ Indeed, a reaction to the increased demands for board and shareholder formal control seems to be building in both policy and business circles as evidenced by the Securities and Exchange Commission's (SEC) April 4, 2007 decision to revisit the Sarbanes-Oxley act, the recent explosive growth of lightly regulated Alternative Investment Market (AIM) in London, and, perhaps by the expanded role of private equity financing. ${ }^{3}$

Surprisingly, both initial pro-reform actions and the subsequent anti-reform reactions occurred in the absence of an integrated theory of governance. At the very least, such a theory of governance should recognize that neither well designed Chief Executive Officer (CEO) incentives nor independent board vigilance, the focus of most policy makers' interest, are essential to effective corporate governance. Functioning firms have been able to thrive without either incentive compensation or outside board oversight. Indeed, insider boards and fixed salary compensation were quite common in widely-held U.S. corporations throughout the nineteenth and early twentieth centuries [see ?)]. Thus, it seems that a truly comprehensive theory of governance should try to also incorporate other checks on managerial behavior - such as the manager's valuation of his long-run relationship to the firm, the rights of owners (both shareholders and creditors) to liquidate corporate assets, and the ability of outside shareholders to use their share voting rights to counter management incentives - into its analysis.

In this paper, we develop a model that includes these factors, as well as board monitoring and CEO compensation. Initially, we abstract from the effect of takeover markets and the problem of opportunism by board members and activist investors. We find that a key determinant in identifying the optimal mechanism is the liquidity of the firm's assets. Liquidity is measured by

\footnotetext{
${ }^{1}$ See http://www.euractiv.com/en/financial-services/corporate-governance/article-137147.

${ }^{2}$ See, for example, http://www.nytimes.com/2007/04/19/business/19pay.html/ref=business, for discussion on the current "say on pay" debate.

${ }^{3}$ See "Buffetology for Wall Street," The Economist, March 15, 2007 for an article on recent attempts to rewrite Sarbanes-Oxley.
} 
the price the firm's assets can command if operation under current management is terminated and they are sold on the secondary asset market. Liquidity could rest either on piecemeal liquidation, such as investors cashing out of a mutual fund, or, it could be based on the the option to transfer en bloc all of the firm's assets. For example, in the Calpine bankruptcy, over $\$ 25$ billion worth of power generation assets changed hands without any appreciable negative effect on the cash flows generated by these assets. As ?) points out, such large scale low-cost asset transfers are becoming routine.

Our analysis shows that, when assets are sufficiently liquid, independent board monitoring and relationship investor activism are both superfluous and wasteful. Instead, the desideratum for effective governance is a simple mechanism by which owners can force asset liquidation. This threat, combined with high compensation, is sufficient to make the CEO fear redeployment, and hence is an cheap and efficient control mechanism. In our formal analysis, this control transfer is implemented by shareholder vote. However, an ownership stake held by a large creditor, who is granted liquidation rights, would accomplish the same end. Thus, in high liquidation value firms, we expect somnolent board governance, little shareholder activism, high CEO compensation, and outside owners, either shareholders or creditors, who have clearly defined control rights that allow them to "pull the plug" on the firm. These outside owners need not have specialized monitoring skills as they need only observe firm output in order to effectively utilize their control rights.

Of course, liquidation is sometimes very costly: either because the disclosure environment is poor and hence outside buyers cannot ascertain firm asset values, or because outsiders do not master the technical relation between firm inputs and outputs. The lack of asset liquidity makes the threat of depriving the manager of the firm's asset base incredible. In such a case, the desideratum for effective governance is active monitoring by shareholders who have the skills required to oversee management. In this situation, we show that intervention by "activist shareholders," (investors with monitoring skill) can restrain managerial opportunism. However, intervention equilibria, in which activists are forced to intervene on a regular basis to check management, feature low payoffs both to managers and shareholders. Yet, we find activists can still sometimes be efficient checks on managerial opportunism. The very fact that activist intervention generates low managerial payoffs makes the threat of reaching the intervention equilibrium a deterrent to managerial opportunism, whenever such a threat is credible. The threat will be credible when the value of the firm's assets in place, even when burdened with the additional costs associated with intervention, is higher than their liquidation value, i.e., in the case of very costly liquidation. Thus, optimal governance design requires activist ownership of the firm, with the fraction of activist capital being the smallest amount that makes the threat of intervention credible. Managerial compensation will be generous, and formal governance mechanisms will have little role in controlling managerial behavior.

For firms whose asset base is moderately liquid, neither control through threatened activism nor control through threatened liquidation are effective. In this intermediate case, the only way 
for the firm to avoid the dissipative costs engendered by regular shareholder intervention is to commit to consistent monitoring. Board governance is the desideratum for this commitment. Commitment to monitoring increases expected monitoring costs but has the virtue of reducing the required level of managerial compensation. Thus, for this intermediate range, we expect more formalized governance, under which boards supervise managerial behavior on a regular basis, featuring modest managerial compensation, with the level of the manager's compensation linked to his skill set rather than the "divertability" of the firm's asset base. Thus, both the "good governance" favored by reformers and "rubber-stamp boards" are viable candidates for efficient control mechanisms. Moreover, the comparative statics of the governance regimes are different, implying that cross-sectional test specifications in empirical work need to condition on structural parameters that determine the optimal governance regime.

After deriving the conditions for these three paradigmatic forms of corporate governance, we then rationalize many other observed governance styles by relaxing our model assumptions to account for two other factors - an active market for corporate control and opportunities for the monitors themselves, whether activists or board members, to divert corporate resources. The threat of a takeover loosens the ties between management and the firm and affects the manager's valuation of his continuing relation to the firm. By undermining the effectiveness of compensation policy, a crucial support for direct shareholder control, the takeover threat favors board control. The introduction of board and activist opportunism alters both the structure of activist ownership, and the design of corporate boards. Further, by raising the relative cost of monitoring through boards, monitor diversion tilts the governance structure towards direct shareholder control. This analysis generates an extensive set of testable predictions regarding corporate governance:

- Management compensation is higher under direct shareholder control as opposed to board control.

- Management compensation is highest for high and low liquidity firms.

- Management compensation will rise with the likelihood of takeovers and will be more sensitive to the threat of a takeover under shareholder control.

- Management compensation is increasing in asset opacity.

- In the absence of mandatory restrictions, firms with high and low asset liquidity will have more passive boards and less sophisticated governance mechanisms.

- In economies where takeover activity is high, firms will rely more on board governance.

- Diffusion of shareholder ownership will be lowest for firms with illiquid and opaque assets.

- Increasing the corruptibility of board members will lead to less reliance on board control, and raise the overall cost of board control, but may lower the incidence of board malfeasance. 
- If the market for corporate control is impeded, large block-holding and board activism increase.

- Shareholder intervention will be positively correlated with the premium paid by activists for block acquisition.

- Absent mandatory restrictions, the better the legal regime, the larger the fraction of management affiliated directors on the board.

- Weakening the protection of minority shareholders can lead to both less board vigilance and better firm performance.

Because our work attempts to embrace a broad array of governance choices, it relates to a wide spectrum of theoretical research. In fact, in pursuing this goal of breadth we have, of necessity, incorporated many specific governance factors in more stylized fashion than much of the existing literature. Like ?), we model the market for corporate control as a check on managerial private benefits. In their analysis, managers, by buying shares, can influence the likelihood of takeovers. In our analysis, however, managers only influence takeover activity through the performance they engender. As in our analysis, ?) assume that activist shareholders can intervene to improve firm performance. They permit activists to trade on secondary markets and assume an exogenous ownership structure. We do not allow secondary market trading but do allow for multiple activists, and focus on optimal ownership structures. When we consider investor activism, we also abstract from its effect on the managers' choice of investment policy as modeled by ?). Instead, we assume the manager's only choice is whether to operate a fixed investment in the interest of shareholders. Thus, per se, in our analysis, activist ownership always improves performance. However, we assume that activist capital is more costly than non-activist capital and thus $100 \%$ activist ownership is not optimal. We also consider, like ?), the role of the level of compensation in aligning managerial and shareholder interests. Because these authors allow managers to pick investment policy, they obtain the result that in some cases committing to low compensation improves shareholder/managerial alignment. Because we assume a fixed investment frontier, we find that increased compensation always improves alignment. However, in our setting, it may not be a particularly efficient way of procuring alignment. ?) model the effect of board composition and voting procedures on performance. We abstract from voting strategy and assume a specific relation between board structure and performance - greater outsider representation increases board effectiveness. Finally, our model resembles ?), like whom we show that competition among opportunistic insiders can be beneficial to outside shareholders.

The rest of the paper is organized as follows. In Section 1., we describe the basic structure of our model. In Section 2., we present a detailed analysis of equilibria in the basic model, where we consider and compare monitoring by investors, and by a board of directors. The remaining sections are devoted to examining extensions of our basic model. In Section 3. we examine the effect of the emergence of a corporate raider. Section 4. extends the basic model 
to include opportunism on the part of activist investors. In Section 5., we present an extension incorporating opportunism by insider directors on the board. In Section 6., we present some preliminary analysis relating corporate governance choices to the prevalent legal regime. Finally, Section 7. concludes the paper. The appendix contains formal proofs of all results in the paper not contained in the text.

\section{Model}

Consider a firm operating in a world populated by infinite-lived risk-neutral agents. The firm is run by a manager who can behave opportunistically. It is owned by investors who initially contribute a total of $\$ 1$ (in equal amounts) to capitalize the firm. These investors are of two types: activists, who can both monitor the manager and decide on whether or not to liquidate the firm, and passive investors who can only decide on liquidation. ${ }^{4}$ The firm has $N_{A}$ activist investors, each of whom owns claims to $\zeta$ percent of the firm's equity while passive investors own the remainder $1-\zeta N_{A}$. Passive investors require a return equal to $r$, the risk-free rate. Activists, however, because they incur fixed costs associated with activism, require a return of $r_{A}>r$. We assume that effective monitoring by each activist requires a shareholding of at least $\underline{\zeta}$.

The firm is able to operate in each period in which it maintains capital of $\$ 1$. This capital allows it to generate a risky cash flow, $\tilde{X}$ at the end of the period. This cash flow depends on an observable but unverifiable state of the world. The state of the world is revealed at the end of the period. The firm's cash flow equals $h$ when the state of the world is $H$ and equals $l$ when the state of the world is $L$. State $H$ occurs with probability $\rho$, and state $L$ occurs with probability $1-\rho$. If the firm does not maintain its capital at $\$ 1$, it generates a cash flow of 0 .

The manager is compensated every period for managing the firm according to a contract that pays $w$ in the $H$ state, and 0 in the $L$ state. At the beginning of every period that he manages the firm, the manager can attempt to divert part of the firm's cash flow for personal consumption. He incurs a cost of $f$ if he chooses to divert and no cost if he decides not to divert. Activists can block managerial opportunism by directly monitoring the manager. Each activist makes her monitoring decision independently at the beginning of each period. If an activist chooses to monitor the manager, she incurs a cost of $c<l$. Activists incur no cost if they choose not to monitor. The manager can only divert if the cash flow $h$ is realized, and is successful only if he is not blocked by activists. If successful in his attempt at diverting cash flow, the manager appropriates $h-l$, leaving investors the remainder of $l .^{5}$

At the end of each period, investors jointly decide whether to remain invested in the firm. If they choose to stay invested, with the exception of the $\$ 1$, all cash flows net of the manager's

\footnotetext{
${ }^{4}$ As stated earlier, we are considering asset liquidity in its broadest sense, i.e., the ability to sell assets piecemeal as well as in toto.

${ }^{5}$ It is reasonable to restrict managerial diversion to the unverifiable portion of cash flows, $h-l$, because a manager, being an employee of the firm, has no rights to dispose of corporate assets beyond those extended by his contract with the firm. No legal system we are aware of limits the board's rights to recover assets verifiably diverted by any employee, including the CEO.
} 
appropriation and compensation are paid out as a dividend. The firm then enters the following period with a corpus of $\$ 1$. If investors decide to shut down the firm they can liquidate its assets and in addition to the net cash flow earned in that period, they also receive the liquidation value of the firm's assets, which is its market value of $\$ 1$ less a fractional discount of $\lambda \in[0,1]$, which may be interpreted as an index of asset liquidity. If the firm is liquidated, the manager has to seek alternative employment. Following the manager's separation from the firm because of liquidation, he is able to command a per-period wage of $\bar{v}$, his per-period reservation wage.

Let $\mathcal{V}$ represent the present value of cash inflows to the firm (to passive, non-activist investors) in the absence of opportunism by the manager or activists, gross of any payment to the manager. It follows that:

$$
\mathcal{V}=\frac{[\rho h+(1-\rho) l]}{r} .
$$

To focus on interesting regions of the parameter space, we make the following assumptions:

Assumption 1. $\mathcal{V}-\frac{\bar{v}}{r}>\frac{r_{A}}{r}$.

Assumption 2. $f<r \mathcal{V}-l-\bar{v}$.

Assumption 3. $l+f<r$.

Assumption 1. ensures that, in the absence of opportunism by the manager, investing in the firm is a positive Net Present Value (NPV) transaction and thus investors have an incentive to contribute capital to the firm. Assumption 2. ensures that appropriation of cash flows by the manager is rational. Assumption 3. implies that investors will earn a negative NPV if they capitalize the firm and subsequently permit the manager to divert cash flows in every period, even if they are able to recover from the manager an amount equal to his periodic cost of diversion $f$.

\section{Monitoring without dissipation}

In this section, we first examine three sets of outcomes when shareholders can restrict managerial opportunism through direct control of the firm. Then we compare direct shareholder control with board control. First, we focus on outcomes where the manager and investors play stationary strategies, i.e., they play the same strategies every period. Next we examine outcomes supported by the adoption of non-stationary strategies by both shareholders and the manager. The first set of non-stationary outcomes result in the adoption of stationary strategies by both shareholders and the manager following the first incidence of opportunism by the manager. The second set of non-stationary outcomes result in the liquidation of the firm following the first instance of opportunistic behavior by the manager. We end the section by demonstrating that in many instances, direct shareholder control dominates board control. In all three instances, we focus on symmetric strategy equilibria. 


\subsection{Stationary outcomes}

First note that no stationary equilibrium exists where the firm is financed, and where there is no monitoring. This follows because in any stationary equilibrium in which the manager is not monitored, it is optimal for him to divert cash flows with certainty. However, Assumption 3. ensures if the manager diverts with certainty, investing in the firm is a negative NPV transaction for investors and thus they will not finance the firm.

We now characterize equilibria where activists monitor along the equilibrium path. First note that there must be some probability of cash flow diversion by the manager for monitoring to be optimal for activists. At the same time, if activists are monitoring with certainty, diversion is never optimal for the manager.

Proposition 1. In any stationary equilibrium, both the manager and the activists must be playing randomizing strategies.

Let $\theta$ represent the probability that the manager attempts to divert in a given period, and let $\pi$ be the probability that an individual activist investor monitors in a given period. It follows that, with $N_{A}$ activists, the probability that the manager is monitored in each period is given by:

$$
\Pi=1-(1-\pi)^{N_{A}}
$$

Let $w_{r}$ represent the compensation to the manager in state $H .{ }^{6}$ Then, the manager's expected payoff if he diverts is:

$$
\rho \Pi w_{r}+\rho(1-\Pi)(h-l)-f
$$

and that if he does not divert is:

$$
\rho w_{r} .
$$

For the manager to be willing to randomize between diverting and abstaining, he must be indifferent between the two alternatives. Using (3) and (4), it follows that the manager will be willing to randomize if:

$$
1-\Pi^{*}=\frac{f}{r \mathcal{V}-l-\rho w_{r}}
$$

Similarly, to randomize between monitoring and not monitoring the manager, each activist has to be indifferent between the two alternatives. Let $E_{m}$ represent the expected end-of-period payoff to each activist conditional on at least one activist monitoring the manager, and let $E_{n m}$ represent the expected end-of-period payoff in the absence of any monitoring. It follows that

\footnotetext{
${ }^{6}$ Note that this represents an optimal compensation design because by concentrating the manager's compensation in state $H$, the manager's incentive to divert cash flow is minimized.
} 
$E_{m}$ and $E_{n m}$ can be written as:

$$
\begin{aligned}
E_{m} & =\zeta\left(r \mathcal{V}-\rho w_{r}\right), \text { and } \\
E_{n m} & =E_{m}-\theta \zeta\left(r \mathcal{V}-l-\rho w_{r}\right)
\end{aligned}
$$

Then, if $1-\tau=(1-\pi)^{N_{A}-1}$ represents the probability that none of the remaining investors are monitoring, the indifference condition for an individual activist can be written as:

$$
\left[\tau E_{m}+(1-\tau) E_{n m}\right]=E_{m}-c .
$$

In the following lemma, we characterize firm value when both activists and the manager adopt the randomizing strategies described above.

Lemma 1. In any stationary symmetric mixed strategy equilibrium where the manager diverts resources with positive probability and the activists monitor with positive probability, the manager's wage equals $\frac{\bar{v}}{\rho}$. This results in a firm value of

$$
\left(\frac{\zeta N_{A}}{r_{A}}+\frac{1-\zeta N_{A}}{r}\right)(r \mathcal{V}-\bar{v})-\frac{c N_{A}}{r_{A}}-\frac{c\left(1-\zeta N_{A}\right)}{\zeta r}\left(\frac{f}{r \mathcal{V}-l-\bar{v}}\right)^{\frac{1}{N_{A}}}
$$

Each activist monitors the manager with probability

$$
\pi^{*}=1-\left(\frac{f}{r \mathcal{V}-l-\bar{v}}\right)^{\frac{1}{N_{A}}}
$$

and the manager diverts cash flows with probability

$$
\theta^{*}=\frac{c}{\zeta f}\left(\frac{f}{r \mathcal{V}-l-\bar{v}}\right)^{\frac{1}{N_{A}}}
$$

As the above result demonstrates, in stationary equilibria, firm value is maximized by setting the manager's expected payoff from employment with the firm equal to his reservation wage. Further, the intensity of monitoring by activists is sufficiently high to ensure that the manager's expected gain from diversion,

$$
\left(1-\Pi^{*}\right)(r \mathcal{V}-l-\bar{v})-f
$$

equals zero.

We now characterize both the optimal number of activists and their ownership stake in the outcome described above. First, note that each activist acts independently of the others. Thus, even though only one activist has to monitor to block diversion by the manager, there may be instances where multiple activists simultaneously choose to monitor the manager. Because monitoring is costly, and the monitoring cost is reflected in the value that activists attribute to the firm's shares, simultaneous monitoring by multiple activists is both wasteful and results in 
a lower firm value. Thus, as we demonstrate in the following lemma, firm value is maximized if only one activist holds shares in the firm.

Lemma 2. In any stationary symmetric mixed strategy equilibrium where the manager diverts resources with positive probability and the activists monitor with positive probability, firm value is maximized by setting the number of activists, $N_{A}^{*}=1$.

Now consider the optimal ownership stake of the single activist. Because the activist requires a higher rate of return on her investment, there is an incentive to try and minimize the activist's ownership stake. However, the activist's incentive to monitor is also tied to her ownership stake. The larger the activist's ownership stake, the greater her incentive to incur the fixed cost of monitoring and thereby limit the diversion of cash flow by the manager. Thus, in equilibrium the activist's ownership stake increases with the manager's propensity to divert cash flows.

Lemma 3. In any stationary symmetric mixed strategy equilibrium where the manager diverts resources with positive probability and the activist monitors with positive probability, firm value is maximized by setting the sole activist's optimal ownership equal to:

$$
\zeta^{*}=\max \left(\underline{\zeta}, \frac{c}{r \mathcal{V}-r_{A}-\bar{v}},\left[\frac{\frac{c f}{(r \mathcal{V}-l-\bar{v})}}{\left(1-\frac{r}{r_{A}}\right)(r \mathcal{V}-\bar{v})}\right]^{\frac{1}{2}}\right)
$$

This optimal ownership stake is non-decreasing in the manager's cost of diversion $f$.

Together, the above results indicate that the ownership structure of firms will be sensitive to the fixed costs of activism and the manager's propensity to divert cash flows, both of which are determined by the level of opacity regarding the firm's operations. To minimize the deadweight costs of monitoring, the claims may be held by multiple passive investors, but only one activist will acquire claims in the firm. Further, when the fixed costs of activism are high, as the differential between the discount rate employed by activists and passive investors increases, activists will hold smaller ownership stakes. However, their ownership stakes will be nondecreasing in the manager's propensity to divert cash flows.

\subsection{Equilibria with randomization as the off-equilibrium threat}

If the manager is not monitored, he will divert with probability one in any stationary outcome. Thus, only in non-stationary equilibria is there the possibility that managerial diversion is deterred without shareholder monitoring. As is typically the case with multi-period models, there exist many non-stationary equilibria where the strategies of agents vary with the history of actions of the other agents. Our goal is not to exhaustively characterize all these equilibria, but to identify those equilibria that maximize value to investors. To deter the manager from diverting, his future employment gains from eschewing diversion must equal at least his single 
period gain from diverting cash flows plus his future reservation payoff. Any equilibrium in which this lower bound for managerial compensation is attained maximizes the firm's payoff across equilibria where diversion does not occur. Hence, we focus on and characterize equilibria having this outcome.

One equilibrium that attains this bound on managerial compensation requires that investors pay the manager an "efficiency wage," i.e, a premium relative to his reservation wage, so long as he does not divert. Subsequent to his first diversion, both the manager and investors revert to stationary strategies like those described above.

\section{Proposition 2. If}

$$
\begin{array}{r}
1-\lambda \leq \frac{l}{r_{A}}, \\
r(\mathcal{V}-\mathcal{B})-\bar{v} \geq r_{A}, \\
\text { and } \underline{\zeta} \leq \frac{c}{r \mathcal{B}}, \\
\text { where } \mathcal{B}=\frac{r \mathcal{V}-l-f-\bar{v}}{r+\rho},
\end{array}
$$

are satisfied, there exist non stationary equilibria with the following characteristics:

a. Firm value is given by

$$
V_{F, E}=\left[\frac{\zeta}{r_{A}}+\frac{1-\zeta}{r}\right][r(\mathcal{V}-\mathcal{B})-\bar{v}]
$$

b. Activists do not monitor the manager so long as he has not diverted cash flows. In all the periods subsequent to the one in which the manager diverts for the first time, each activist monitors the manager with probability

$$
\pi^{*}=1-\left(\frac{f}{r \mathcal{V}-l-\bar{v}}\right)
$$

and the manager diverts with probability

$$
\theta^{*}=\min \left[\frac{c}{\zeta(r \mathcal{V}-l-\bar{v})}, 1\right] .
$$

c. In these equilibria, the present value of the manager's compensation is equal to $\mathcal{B}+\frac{\bar{v}}{r}$.

d. The optimal fraction of ownership per activist investor is given by

$$
\zeta^{*}=\max \left[\underline{\zeta}, \frac{c}{r \mathcal{V}-l-\bar{v}}\right]
$$

and the number of activist investors is $N_{A}^{*}=1$. 
Note that in such non-stationary equilibria, activism only serves as an off-equilibrium threat. A minimum level of activist ownership is required to ensure that activists have incentives to play the stationary monitoring strategies required of them. Any increase in activist ownership above this minimum is counterproductive because of their higher required rate of return. Because the total activist stake can be minimized by having only one activist, as in the stationary case, ownership by only one activist is optimal. Further, for randomized monitoring by the activist to be a credible off-equilibrium path threat, this strategy has to maximize firm value given the activist's beliefs regarding the manager's future actions. As the above proposition demonstrates, randomized monitoring subsequent to the first diversion by the manager is optimal only if the liquidation value of the firm's assets is sufficiently low.

The above result demonstrates that non-stationary equilibria, while they might eliminate the need for monitoring on the equilibrium path, are not costless. They require that the manager receive an "efficiency wage", as well as a minimum level of ownership by an activist who requires a high rate of return. These costs might be lowered if the firm's assets are sufficiently liquid.

\subsection{Equilibria with liquidation as the off-equilibrium threat}

If the manager is separated from the firm because it is liquidated, he is only able to command a per-period wage of $\bar{v}$. He will be willing to eschew appropriating firm cash flows only if his gain this period from doing so is no larger than the expected loss of future income because of the firm's liquidation. Further, the manager's compensation must also be sufficiently high to ensure that he is willing to work for the firm. Thus, as demonstrated below, the manager may

receive a wage higher than his reservation wage, and the present value of the premium relative to his reservation wage is given by $\mathcal{B}$, defined in (17).

The strategy of liquidating the firm is rational so long as investors believe that once the manager acts opportunistically, he will do so in every future period. Further, the cost of liquidating assets has to be relatively small.

\section{Proposition 3. If}

$$
\begin{array}{r}
1-\lambda \geq \frac{l}{r}, \\
\text { and } r(\mathcal{V}-\mathcal{B})-\bar{v} \geq r
\end{array}
$$

are satisfied, there exist equilibria where investors do not monitor the manager and the manager does not divert. These equilibria have the following characteristics:

a. Firm value is given by

$$
V_{F, E}=\frac{1}{r}[r(\mathcal{V}-\mathcal{B})-\bar{v}]
$$

b. If the manager diverts, investors liquidate the firm.

c. The present value of the manager's compensation is equal to $\mathcal{B}+\frac{\bar{v}}{r}$. 
Note that these non-stationary equilibria are different from those described earlier in section 2.2. because of the operative off-equilibrium path threat that investors are able to employ to prevent the manager from diverting. In the first equilibrium, if the manager is caught diverting, investors will switch to actively monitoring the manager but monitoring is sufficiently lax to permit opportunism by the manager. This requires that activists retain a minimum ownership stake in the firm. On the other hand, in the non-stationary equilibria described in this section, diversion by the manager precipitates liquidation of the firm and the consequent firing of the manager. This does not require the presence of activists, and thus in non-stationary equilibria featuring the off-equilibrium path threat of liquidation, firm value is maximized by an ownership structure that features only passive investors.

\subsection{Monitoring by a board}

Thus far, we have examined optimal governance structures when investors are restricted to directly monitoring the manager. However, direct monitoring is not the only means by which investors can control managerial opportunism. An alternative to direct monitoring is the constitution of a board to which investors can delegate the monitoring function.

Hiring monitoring services is only feasible if monitoring can be verified. Even if monitoring can be verified, it will in general be difficult to verify a randomized monitoring strategy as no finite sample of monitoring choices by agents could conclusively prove that a given random strategy is not being followed [see ?)]. Thus, even if monitoring is verifiable, it is only feasible to commit to deterministic monitoring.

Board monitoring, like activist monitoring, is costly. It is not obvious whether this cost is more or less than activist monitoring. ${ }^{7}$ On the one hand, board monitoring costs might be higher because activists could capture economies of scale through monitoring multiple firms simultaneously. On the other hand, boards have superior rights to internal information. This may lower their cost of monitoring relative to outside activists. Because we have no strong $a$ priori reason to believe that board monitoring costs are greater or less than outside activists' monitoring costs, we do not want to derive comparisons that depend on these cost differences. For this reason, we assume that the cost of board monitoring, $b$ equals the cost of activist monitoring:

Assumption 4. $b=c$.

Board monitoring has certain advantages over activist monitoring. First, the board permits pre-commitment to monitoring. Thus, when shareholders appoint a board, the manager knows his actions will be monitored and he cannot gain from diversion. For this reason the manager will not divert even if he is only paid his reservation wage. Consequently, the firm avoids the cost of managerial diversion without paying the cost of bribing the manager through an

\footnotetext{
${ }^{7}$ In Sections 4., 5., and 6. below we explicitly examine the effect of differences in the cost of activist and board monitoring.
} 
efficiency wage. Further, because activist ownership is not required, all firm cash flows can be allocated to non-activist shareholders who have a lower required rate of return. In addition, the costs of monitoring duplication, which can be incurred with multiple activists, are avoided. However, there is one disadvantage of board control. It requires certain monitoring and certain monitoring may be excessive if only a small likelihood of monitoring or the mere threat of monitoring is required to deter managerial diversion. For this reason alone, board control may be sub-optimal.

Proposition 4. a. Board control results in firm value of

$$
\frac{1}{r}(r \mathcal{V}-\bar{v}-c)
$$

and dominates direct monitoring by shareholders when firm assets display moderate liquidity, i.e.,

$$
\frac{l}{r} \geq 1-\lambda \geq \frac{l}{r_{A}}
$$

b. Board control and activist ownership are sub-optimal when the cost of liquidating the firm's assets $(\lambda)$ and the manager's efficiency wage $\left(\mathcal{B}+\frac{\bar{v}}{r}\right)$ are relatively low.

c. Activist ownership is optimal when the cost of liquidating the firm's assets $(\lambda)$ is relatively high but the manager's efficiency wage $\left(\mathcal{B}+\frac{\bar{v}}{r}\right)$ and the return premium $\left(r_{A}-r\right)$ required by activists are relatively low.

We now illustrate these tradeoffs. We analyze stationary and non-stationary equilibria of the model for a given set of parameters, and compare firm value under direct investor monitoring with that of a board. ${ }^{8}$ Figure 1 illustrates the choice between the various forms of direct shareholder control and board control as a function of $\lambda$, our measure of asset liquidity. In this example, asset opacity, as captured by the cost of monitoring $c$ is set at 0.05 and the cost of stealing by the manager $f=0.20$.

The dotted line represents firm value under the optimal governance mechanism. For low values of $\lambda$, i.e., when assets are very liquid, non-stationary equilibria with the off-equilibrium threat of liquidation dominate. As asset liquidity decreases, the threat to liquidate contingent on diversion by the manager is no longer credible. At intermediate values of $\lambda$, when only randomized direct monitoring is feasible, board control is optimal. At very high values of $\lambda$, when assets are very illiquid, firm value is highest under the non-stationary equilibrium where managerial diversion triggers random monitoring by the activist.

Figure 2 revisits the choice between direct shareholder control and board control for a lower level of asset opacity. Here, $c$ is lowered to 0.0275 (while maintaining $f=0.20$ ), and consequently board control dominates direct shareholder control for all levels of asset liquidity. These figures illustrate our basic thesis that when it comes to corporate governance, one size

\footnotetext{
${ }^{8}$ The assumed values for all parameters in Figures 1 through 11 are provided in Table 1.
} 
certainly does not fit all. The nature of the optimal governance mechanism varies along the nature of the firm's assets.

[Figures 1 and 2 about here]

\section{Raiders and corporate governance}

In this section, we demonstrate that external factors can influence the firm's optimal governance structure. To illustrate such influence, we examine the effect on the firm's optimal governance structure and its value, of the threat of a takeover offer made by a corporate raider.

Suppose that in each period, there is a probability $\kappa$ that a raider could appear and launch a takeover attempt for the firm. If the raider appears, he offers to acquire the firm for $\$ Z$. To enable us to focus on the relation between the threat of a takeover and the optimal governance mechanism, we abstract from issues relating to the optimal structure of the raider's bid and the possibility of competing bids. Further, we assume that the raider's offer price satisfies:

$$
Z \geq \mathcal{V}-\frac{\bar{v}}{r}
$$

that is, the offer price exceeds the (net) value of the firm. Thus, if the raider makes an offer, both activists and non-activist shareholders will prefer to sell the firm to the raider.

Once the raider acquires the firm, he replaces the manager, who then earns his reservation wage in all future periods. The possibility of a takeover thus reduces the manager's expected tenure with the firm. We now proceed to show how this possible change in the manager's expected tenure with the firm tilts the balance toward board governance and away from direct shareholder control.

For a fixed governance structure, the introduction of the raider into our analysis directly affects firm value in two ways. First, because shareholders relinquish control to the raider, the link between operating cash flows and share values has to be conditioned on the appearance

of the raider. Second, share values will reflect the premium paid by the raider. Because management compensation and the ownership structure play no role under board governance, the takeover possibility has a very transparent effect on firm value. Under board control, firm value can be represented as:

$$
(1-\kappa)\left[\frac{r \mathcal{V}-\bar{v}}{r+\kappa}-\frac{c}{r+\kappa}\right]+\frac{\kappa Z}{r+\kappa}
$$

Given that the raider's appearance has no indirect effect on firm value, and because $Z$ is higher than the value of the firm's operating cash flows, firm value must increase with the probability of a takeover under board control.

Next, we examine how the possible appearance of a raider alters firm value when shareholders directly control the firm. First, consider the governance structure under which the manager 
randomly diverts cash flows in every period and activists randomly monitor the manager. Note from our earlier analysis that the manager's diversion decision and activists' monitoring decisions are made every period, and are hence independent of their horizons. Thus, the relation between the strategies of these agents and the activists' ownership stake is unaffected by the introduction of a raider. Further, the takeover threat does not introduce any new tradeoffs regarding the design of management compensation or the wastefulness of including multiple activists in the firm's ownership structure. Consequently, it continues to be optimal to set the manager's expected wage payment equal to his reservation wage and include only one activist in the ownership structure. Thus, firm value as a function of the activist's ownership stake, can be expressed as:

$$
\begin{aligned}
(1-\kappa)\left[\left(\frac{\zeta}{r_{A}+\kappa}+\frac{1-\zeta}{r+\kappa}\right)(r \mathcal{V}-\bar{v})-\frac{c}{r_{A}+\kappa}-\right. & \left.\frac{c(1-\zeta)}{\zeta(r+\kappa)}\left(\frac{f}{r \mathcal{V}-l-\bar{v}}\right)\right] \\
& +\left(\frac{\zeta}{r_{A}+\kappa}+\frac{1-\zeta}{r+\kappa}\right) Z \kappa
\end{aligned}
$$

This expression is very similar to (9) in that it demonstrates that firm value reflects the firm's ownership structure and operating cash flows net of the monitoring cost borne by the activist, as well as the non-activists' losses because of diversion by the manager. However, as is to be expected, these factors are only reflected in firm value conditional on the the firm continuing to operate when no raider materializes. Unlike (9), the above expression indicates that firm value is also a function of both the likelihood of a takeover offer and the price paid by the raider. Given that the manager's per-period salary remains equal to $\frac{\bar{v}}{\rho}$, the only possible indirect effect of the takeover threat on firm value is its effect on the activist's optimal ownership stake. This limited indirect effect contrasts with the effect of the takeover threat on the two non-stationary governance structures that facilitate direct shareholder control.

Management compensation plays a crucial role in the two non-stationary governance structures. Under these two structures, the manager is paid an "efficiency" premium over his reservation wage, and the present value of this premium is chosen to be just large enough to deter diversion. For a fixed wage, a takeover threat, by limiting the manager's horizon, reduces the present value of any premium embedded in the wage. Thus, to deter diversion, the manager's wage has to rise with the likelihood of a takeover. When the possibility of a takeover is considered, the present value of the optimal premium over the manager's reservation wage is given by:

$$
\mathcal{B}_{\mathcal{T}}=\frac{r \mathcal{V}-l-f-\bar{v}}{(1+r)-(1-\kappa)(1-\rho)}
$$

After accounting for this increase in management compensation, firm value when the governance structure does not rely on activists and calls for firm liquidation subsequent to the first instance 
of managerial diversion can be represented as follows:

$$
(1-\kappa)\left[\frac{r \mathcal{V}-\bar{v}}{r+\kappa}-\mathcal{B}_{\mathcal{T}}\right]+\frac{\kappa Z}{r+\kappa}
$$

Note that, in addition to capturing the indirect effect of a possible takeover, this expression also reflects the two direct effects of introducing the raider into our analysis. Similarly, when the governance structure requires an activist in the ownership structure, and both the manager and activists adopt mixed strategies following the first instance of managerial diversion, firm value can be represented as: ${ }^{9}$

$$
(1-\kappa)\left(\frac{\zeta}{r_{A}+\kappa}+\frac{1-\zeta}{r+\kappa}\right)\left[r \mathcal{V}-\bar{v}-(r+\kappa) \mathcal{B}_{\mathcal{T}}\right]+\left(\frac{\zeta}{r_{A}+\kappa}+\frac{1-\zeta}{r+\kappa}\right) \kappa Z .
$$

In addition to the two direct effects of the raider's introduction on firm value and its indirect effect on management compensation, the takeover threat also has a more subtle effect on the feasibility of the two non-stationary governance structures. Shareholders realize that by liquidating the firm's assets they will forgo the takeover premium that they would enjoy if a raider materializes, thus raising their deadweight loss from liquidation. It follows that, even if a non-activist shareholder believes that the manager will choose to divert in every period subsequent to the first diversion of firm assets, he will be willing to liquidate the firm only if:

$$
1-\lambda \geq \frac{l}{r+\kappa}+\frac{\kappa Z}{r+\kappa}
$$

This higher liquidation cost reduces the range of parameter values that support the governance structure that calls for firm liquidation following managerial diversion. On the other hand, it increases the range of parameter values that support the governance structure that calls for the manager and activist shareholders to adopt stationary mixed strategies following the first instance of managerial diversion.

The raider's introduction also has a second subtle effect. It supports a governance structure where no activists are included in the ownership structure and the manager does not divert. Subsequent to the first instance where the manager diverts, his wage is set to zero and he diverts in every future period. Because he receives a wage of zero, and he diverts in every period after he first diverts, the manager has to be paid the following premium every period to deter diversion on the equilibrium path:

$$
\frac{r \mathcal{V}-l-f-\bar{v}}{\rho}
$$

Conditional on the firm continuing to operate, shareholders receive all cash flows less the man-

\footnotetext{
${ }^{9}$ Note that once again, given that the stationary strategies that are adopted are not influenced by the introduction of the raider except through the effect of the raider on the activists' ownership stake, it will continue to be optimal to include only one activist in the ownership structure.
} 
ager's compensation in every period. Thus, firm value equals

$$
\frac{l+f+\kappa Z}{r+\kappa}
$$

As is clear from this expression for firm value, given Assumption 3., the only reason that shareholders ever invest in the firm is that they anticipate a takeover that will pay a substantial premium. As Figure 3 illustrates, this governance structure may dominate both board governance and other forms of direct shareholder control when the firm faces an elevated takeover threat. To generate this figure we set $\kappa=0.25, Z=1.574$, and all the remaining parameters are set equal to their values used to generate Figure 2. The elevated threat of a takeover makes it infeasible for shareholders to use liquidation as a disciplining mechanism. Further, it raises the manager's efficiency wage in the other non-stationary direct shareholder control structure, making it relatively unattractive. Finally, given the relative opacity of the firm's operations, shareholders find board governance relatively costly and resort to it only when active monitoring of the manager is the only feasible alternative. This example demonstrates how the threat of a takeover can lead a firm to abandon all attempts develop internal governance mechanisms.

Figure 4 illustrates how a slightly lower takeover threat can tilt firms toward adopting board control. In this figure, we juxtapose firm values in two cases: a) when there is no takeover threat, and b) when $\kappa=0.15$, and $Z=1.462$. All the remaining parameters are set equal to their values used to generate Figure 1. When $\kappa=0$, as illustrated in Figure 1, direct shareholder control is optimal at both end of the liquidity spectrum and board control is optimal only for intermediate levels of liquidity. When $\kappa$ rises to 0.15 , firm value under board control rises. However, firm value conditional on shareholder control falls at both extremes of the liquidity spectrum. Because of this decline in firm value conditional on direct shareholder control, board governance emerges as the best alternative for a large range of liquidation values. Further, the switch to board governance results in a decline in firm value. Thus, the emergence of a raider can both reduce firm value and alter the balance between direct shareholder control and board control.

[Figures 3 and 4 about here]

\section{Opportunistic monitoring by shareholders}

Thus far, we have assumed that activist investors generate benefits for themselves only through increasing the welfare of all investors. However, as noted by ?) and ?), activism is not always this innocuous. First, dealing with activists imposes real costs on the firm. ${ }^{10}$ Activists have their own private interests and this provides them with an incentive to influence firms towards projects that further those private interests. For example, pension funds which face

\footnotetext{
${ }^{10}$ Examples of such costs include legal fees that firms have to incur to combat challenges by activists. Firms may also be forced to increase disclosure of proprietary information that may erode their competitive advantage.
} 
zero marginal tax rates on distributions would have an incentive to demand that firms disgorge cash flows to investors even when such payments may not be in the interests of the marginal investor. Since activists may also gain a reputational benefit from monitoring in addition to any value improvement in their holdings, they may have an incentive to over-monitor. At the same time, an opportunistic activist will find it difficult to force the firm into adopting policies that benefit only himself at the expense of other activists. ${ }^{11}$

We capture the effects of activist opportunism described in the previous paragraph by assuming that monitoring by activists results in the diversion of a fraction of profits. Because opportunistic policies that provide at least some benefit to the entire set of activists are likely to succeed, we assume, for simplicity, that any gains from activism are split equally among the set of activists. Let $\delta<1$ represent the proportion of cash flow diverted because of activism. Thus, if firm profit in the absence of activism is $x$, following activism, the profit available to distribute to investors is given by $x(1-\delta)$. To capture the dissipative nature of activism, we assume that the gain to activists as a whole from their activities is given by $x \delta \alpha$, where $\alpha<1 .^{12}$

One might imagine that accounting for opportunism by activists would reduce firm value and discourage the use of activism as a mechanism to control managers. Indeed, the direct negative costs of activism will make control through activism less attractive. This effect has been informally discussed in both ?) and ?). However, by formally modeling opportunism, as the following analysis reveals, we can identify a positive effect even to passive investors from permitting activists to extract private benefits from activism.

When the gains from activist diversion are sufficiently large, activists are able to commit to monitoring the manager even when he does not divert. To see this note that, if activists monitor, each of them receives an end-period payoff of:

$$
E_{m}=\left[\zeta(1-\delta)+\frac{\alpha \delta}{N_{A}}\right](r \mathcal{V}-\rho w)
$$

An activist will be willing to monitor so long as his payoff from monitoring exceeds his payoff

\footnotetext{
${ }^{11}$ While it may be difficult and costly for passive investors to decipher the valuation effects of the manager's actions, it should be relatively easy for one activist to identify the private benefits from firm policy imposed by another activist. Thus, policies for the exclusive benefit of one activist are likely to be blocked.

${ }^{12}$ As argued earlier, it is reasonable to restrict managerial diversion to the unverifiable portion of cash flows, $h-l$. However, the case for restricting shareholder diversion to unverifiable assets is much weaker. Minority shareholders cannot impose contractual restrictions on diversion by controlling shareholders, and so their only protection is through legal recourse. The power of controlling shareholders in this fashion depends very much on the specifics of the legal regime. In some regimes, e.g., in the large and expanding U.K. equity market of the mid-nineteenth century, minority shareholders had virtually no recourse against majority shareholders (see ?)), while in today's U.S. equity markets, minority shareholders have extensive protection. Thus, we try to capture these differences in a very rough way by assuming that opportunistic monitors can divert both verifiable and unverifiable cash flows but that their diversion is limited to a fraction of available cash flows. Later we explicitly examine the effects of legal restrictions on activist diversion and governance.
} 
if he does not monitor, i.e.,

$$
\begin{aligned}
E_{m}-c & \geq\left[\tau E_{m}+(1-\tau) E_{n m}\right], \\
\text { where } 1-\tau & =(1-\pi)^{N_{A}-1}=(1-\Pi)^{\frac{N_{A}-1}{N_{A}}}, \\
\text { and } E_{n m} & =\zeta(r \mathcal{V}-\rho w)-\theta \zeta(r \mathcal{V}-l-\rho w) .
\end{aligned}
$$

Thus, an activist will commit to monitoring so long as his equity stake in the firm is sufficiently low, i.e.,

$$
\zeta \leq\left(\frac{\alpha}{N_{A}} \delta(r \mathcal{V}-\rho w)-\frac{c}{(1-\Pi)^{\frac{N_{A}-1}{N_{A}}}}\right) \frac{1}{(\delta-\theta)(r \mathcal{V}-\rho w)+\theta l}
$$

Each activist will monitor with certainty when (39) is satisfied as a strict inequality and will commit to random monitoring when (39) is an equality. Let the level of activist ownership that leaves an activist indifferent to monitoring be represented by $\hat{\zeta}\left(N_{A}, \theta\right)$. Note that $\hat{\zeta}\left(N_{A}, \theta\right)$ is increasing in $\theta$, implying that activists will be more willing to commit to monitoring the higher the likelihood of managerial diversion.

Now suppose that $\underline{\zeta}<\hat{\zeta}\left(N_{A}, 0\right)$, then if each activist owns the minimum stake necessary to be able to influence the firm, activists will monitor the firm with certainty. Consequently the manager cannot divert, and will choose not to. Further, his wage will be set to satisfy his reservation constraint and firm value will be given by:

$$
V_{F}\left(0,1, N_{A}, \zeta\right)=(1-\delta)(r \mathcal{V}-\bar{v})\left[\frac{\zeta N_{A}}{r_{A}}+\frac{1-\zeta N_{A}}{r}\right]+\frac{\alpha \delta(r \mathcal{V}-\bar{v})}{r_{A}}-\frac{c N_{A}}{r_{A}}
$$

The first term in (40) captures the value of the firm net of diversion by activists. The second term captures the impact of the activists gains from diversion on their valuation of their ownership claims, and the final term represents the deadweight cost of monitoring the manager. When the second term in (40) is sufficiently large, it is clear that activists will value their ownership stakes at a premium relative to passive shareholders.

When each activist owns $\zeta$ of the firm and $\underline{\zeta}<\zeta=\hat{\zeta}\left(N_{A}, 0\right)$, each activist is indifferent to monitoring even when $\theta=0$. Thus, it is possible to induce each activist to monitor with a sufficiently high probability such that the aggregate level of monitoring leaves the manager indifferent to diverting, i.e., it is possible to set

$$
\pi=1-\left(\frac{f}{r \mathcal{V}-l-\rho w}\right)^{\frac{1}{N_{A}}} .
$$

Because activists are indifferent to monitoring, their payoffs are equal to their payoffs when they monitor with certainty. However, passive shareholders gain from the reduction in activist monitoring because this reduces their losses from activist diversion. Thus, because it is optimal to set the manager's wage to satisfy his reservation constraint, when activist randomly monitor 
with a sufficiently high probability to deter managerial diversion, firm value is given by

$$
\begin{aligned}
V_{F}\left(0, \Pi, N_{A}, \zeta\right)= & (1-\delta)(r \mathcal{V}-\rho w)\left[\frac{N_{A} \zeta}{r_{A}}+\frac{1-N_{A} \zeta}{r}\right]+\frac{\alpha \delta(r \mathcal{V}-\rho w)}{r_{A}}-\frac{c N_{A}}{r_{A}} \\
& +\frac{\delta(1-\Pi)(r \mathcal{V}-\rho w)\left(1-N_{A} \hat{\zeta}\right)}{r} .
\end{aligned}
$$

The first three terms in this expression are identical to those in (40). The final term in (42) represents the gain to passive shareholders when activists switch from certain to random monitoring.

Finally, if each activist owns $\zeta$ of the firm and $\underline{\zeta}<\zeta=\hat{\zeta}\left(N_{A}, \theta\right)$, activists will continue to randomly monitor the manager who will be indifferent to diverting and will divert with probability $\theta$. Under randomization by both activists and the manager, firm value is given by

$$
\begin{aligned}
V_{F}\left(\theta, \Pi, N_{A}, \zeta\right)= & (1-\delta)(r \mathcal{V}-\rho w)\left[\frac{N_{A} \zeta}{r_{A}}+\frac{1-N_{A} \zeta}{r}\right]+\frac{\alpha \delta(r \mathcal{V}-\rho w)}{r_{A}}-\frac{c N_{A}}{r_{A}} \\
& +\frac{\delta \alpha(1-\Pi)\left(1-N_{A} \zeta\right)(r \mathcal{V}-\rho w)}{r N_{A} \zeta}-\frac{c(1-\pi)\left(1-N_{A} \zeta\right)}{r \zeta} .
\end{aligned}
$$

Once again the first three terms in (43) have the same interpretation as they did in (40). The fourth term represents the gain to passive investors from the switch to randomization by activists and the fifth term represents the loss to passive investors from managerial diversion.

A comparison of (43) with (42) suggests that firm value may be lower when the manager is permitted to divert. This is indeed the case. First, managerial diversion directly reduces the amount of cash flow available to shareholders. Second, from the definition of $\hat{\zeta}\left(N_{A}, \theta\right)$, it follows that, to leave activists indifferent to monitoring the manager, an increase in the probability of managerial diversion has to be accompanied by an increase in the ownership stake of activists. This is costly because activists discount cash flows at a higher rate than passive shareholders. Finally, a switch from an outcome where the manager is deterred from diverting to one where he diverts at random, does not affect the deadweight costs of activism as their valuation of their stake in the firm is fixed at its value under certain monitoring. This insight is formalized in the following result.

Lemma 4. So long as $\underline{\zeta} \leq \hat{\zeta}\left(N_{A}, 0\right)$, there cannot exist equilibria where the manager diverts with positive probability.

Our previous results demonstrate that, absent the potential for private benefits to activists, either the firm incurs dissipative costs from costly monitoring and diversion by the manager, or the firm pays the manager an efficiency wage. The reason the firm is restricted to these two alternatives is that it is not incentive compatible for activists to monitor the manager unless the manager is diverting with positive probability. However, once activism generates private gains, activists have an incentive to monitor even in the absence of diversion by the manager. 
Hence the manager is monitored even where he does not divert, and there is no necessity for an efficiency wage to deter managerial diversion.

While the presence of activists is welcome because they eliminate the need for both an efficiency wage for the manager and the dissipation of value because of managerial diversion, activist ownership may adversely affect firm value because of over-monitoring. Thus, the optimal governance structure has to achieve a fine balance between the deterrent effect of activist ownership on managerial opportunism and its negative consequences because of activist opportunism. In contrast to our earlier results, to attain this balance, the optimal ownership structure may require the presence of multiple activists. The introduction of additional activists into the firm's ownership structure, because it results in the sharing of the private benefit from activism across a larger set of agents, reduces the incentive to over-monitor. Further, this reduced incentive to monitor may allow the firm to reduce the aggregate level of activist ownership. Thus, the presence of multiple activists now has a salutary effect primarily because the free riding associated with more diffused activist ownership tempers the incentive to monitor. Consequently, in some instances, optimal ownership structure can call for multiple activists to own stakes in a firm.

Proposition 5. There exist equilibria where firm value is maximized when more than one activist is present in the ownership structure.

We now illustrate this result and the benefits of activist diversion. Figure 5 illustrates how firm value varies with the number of activists in the firm's ownership structure when each activist maintains an optimal ownership stake. The figure presents firm value for each of the three possible combinations of activist monitoring and managerial diversion strategies. As is clear from the figure, firm value is lowest in outcomes where the manager is permitted to divert. Further, an increase in the number of activists raises firm value by reducing the incentives of activists to monitor. Thus, despite the potential duplication of effort and wastefulness of simultaneous monitoring by multiple activists, because the presence of multiple activists sharply attenuates the incentive of each activist to monitor, total monitoring is reduced, raising firm value.

In addition to influencing the optimal ownership structure, activist opportunism can significantly impact the firm's entire governance structure. Figure 6 provides some insight into the impact of activist opportunism on the firm's governance structure by providing a comparison of firm value under direct shareholder control both when activists act opportunistically and when they do not. The solid line in the figure represents firm value when activists do not act opportunistically and the broken line represents firm value when activists can gain from opportunism. We can see from the figure that, in certain cases, it is advantageous to provide differential rewards to investors who monitor. In the case of activists, these rewards are provided ex post through their gains from opportunism. These opportunism gains come at the cost of the manager who is prevented from diverting firm resources by the activists who monitor 
diligently. Because the activist's gains from opportunism are reflected in their valuation of the firm's shares, so long as there is not a lot of dissipation of value from activist opportunism, firm value increases when opportunism induces enhanced monitoring. As demonstrated below, this salutary effect of opportunism is in direct contrast to the effects of opportunism when the firm opts for board control.

[Figures 5 and 6 about here]

\section{Monitoring by an opportunistic board}

It has long been recognized in the literature that insiders on boards tend to have lower costs of monitoring firm activities than outsiders on the board, but at the same time have more opportunities to act opportunistically. ${ }^{13}$ In this paper, because our focus is not on the micro-structure of boards, but rather on boards as one component in a matrix of governance mechanisms, we will take a reduced form approach to modeling the difference between insiders and outsiders. We capture the monitoring advantage of insiders by assuming they have lower monitoring costs, and we capture the greater incentive conflicts of insiders by assuming that they have an exogenous probability of using their board position to divert firm value.

Total board size is fixed at $n$ members. The fraction of insiders on the board is represented by $\mu$. The per-director cost of constituting a board consisting entirely of insiders is $b_{I}$. On the other hand, the cost per director of establishing a board populated entirely by outsiders is given by $b_{O} \geq b_{I}$. These per-period costs of hiring directors are paid at the beginning of each period. In order for board opportunism to be comparable to our earlier analysis, we make the assumption that

Assumption 5. $n b_{O}=c$.

We model the conflicted nature of inside directors by assuming that they can divert cash flows to themselves if they control the board. Board control by insiders requires that they can outvote the remaining board members. Thus, diversion is possible only if:

$$
\mu \eta>\mu(1-\eta)+(1-\mu)
$$

where $\eta$ is the proportion of dishonest insiders and is drawn from the distribution $F_{\eta}(y)$. Just as in the case with activist diversion, inside directors can divert a fraction $\delta$ of cash flows net of the manager's wage payment. Further, just as assumed previously, the fraction $1-\alpha$ of the diverted cash flows is lost to dissipation.

Given that the board can be reconstituted every period, and that decisions in the current period do not have any effect on the opportunities in subsequent periods, the optimal governance

\footnotetext{
${ }^{13} \mathrm{~A}$ number of authors have identified other sources of insider/outsider differences based on information, succession, bargaining power, etc. See, for example, ?), ?), and ?).
} 
structure is simply a single period optimization problem where investors choose $\mu$ and $w$ to maximize their expected payoff below:

$$
[\rho(h-w)+(1-\rho) l]-\delta[\rho(h-w)+(1-\rho) l]\left[1-F\left(\frac{1}{2 \mu}\right)\right]-n\left[(1-\mu) b_{O}+\mu b_{I}\right] .
$$

Note that with a board there is always monitoring, and thus the manager cannot divert. Consequently, he will receive his reservation wage in every period and the investors' problem reduces to one of choosing $\mu$ and $w$ to maximize:

$$
[r \mathcal{V}-\bar{v}]-\delta[r \mathcal{V}-\bar{v}]\left[1-F\left(\frac{1}{2 \mu}\right)\right]-n\left[(1-\mu) b_{O}+\mu b_{I}\right]
$$

Setting the first order condition of this maximization problem to zero and simplifying yields the optimal fraction of insiders as the solution to:

$$
n\left[b_{O}-b_{I}\right]-\delta[r \mathcal{V}-\bar{v}] f\left(\frac{1}{2 \mu}\right) \frac{1}{2 \mu^{2}}=0
$$

Even though insiders can divert firm cash flows, this is not feasible until they account for at least half the board, i.e., $\mu \geq \frac{1}{2}$. Insider representation, however, is determined by the functional form of the distribution $F$. From inspection of the above first order condition, it is obvious that, if $f(1)=0$, which must be the case if the density is continuous over the real line, then evaluated at $\mu=1 / 2$ the derivative is positive, implying that the optimal level of insider representation is greater than $1 / 2$. On the other hand, if the density evaluated around 1 is bounded away from 0 , as would be the case for example with a uniform distribution of $\eta$, then $\mu=1 / 2$ is potentially an optimal policy. Unless the density function for $\eta$ is decreasing at a rapid rate, optimal designs tend to be either $50 \%$ insider representation or all insider representation. When the density is decreasing rapidly, for example if $\eta$ follows a Pareto distribution where:

$$
f_{\eta}(t)= \begin{cases}\frac{2 a^{2}}{\left(1-a^{2}\right) t^{3}} & \text { if } t \in[a, 1], \\ 0 & \text { Otherwise }\end{cases}
$$

at the extreme solution of $\mu=1$, the likelihood of insider being dishonest declines rapidly which supports displacing some insiders with outsiders by lowering $\mu$.

Interestingly, when the optimal level of insider participation is interior, i.e., between $1 / 2$ and 1, an increase in the expected honesty of insiders can lead to an increase in the likelihood of diversion. This occurs because, at higher levels of honesty, the optimal number of insiders on the board rises at a rate that more than offsets the lower likelihood of a given insider being dishonest. The total cost, which includes directorial compensation as well as expected losses from diversion, however, decreases with an increase in insider honesty.

Proposition 6. Increases in the honesty of directors, measured by first-order stochastic dominance always lower the total cost of the agency problem. However, increased honesty may 
increase the likelihood of diversion.

We proceed to illustrate these results. Figures 7 through 9 illustrate some issues in the above discussion, especially, the last proposition. It can be seen that the fraction of inside directors, firm value, and the likelihood of diversion, all increase as honesty increases.

[Figures 7 through 9 about here]

In Figure 10, we compare firm value with opportunistic activists (see Section 4.) and that with an opportunistic board. Here a diverting board dominates activist diversion completely, and the recapture of value diverted by activists is not enough to offset the drop in value due to a higher activist discount rate.

Figure 11, shows the opposite case, where activist monitoring dominates monitoring by the board. The first reason is that the discount rates for activist and passive investors are close to each other $\left(r_{A}=0.2401\right.$, and $\left.r=0.24\right)$, which leads to very low loss in firm value due to diverting activists. The second and more important reason is that money diverted by opportunistic insiders is lost forever, while that diverted by activists finds its way back into firm value through security valuation.

[Figures 10 through 11 about here]

\section{Rule of law}

Thus far we have assumed that the reward for opportunism is exogenous. However, changes in the legal environment and regulations should affect the rewards from opportunism. Moreover, legal systems are designed to raise the costs of opportunistic behavior. Thus, it seems natural to view the rewards of opportunism as being determined by the nature of the legal system. A simple way to impose this dependence is to assume, as we do in the sequel, that investors, by paying the cost $\Gamma$, can completely recover all the cash flows diverted by opportunistic board members and activists.

Let $s_{H}\left(s_{L}\right)$ represent the amount that dishonest monitors divert in state $\mathrm{H}(\mathrm{L})$. Both $s_{H}$ and $s_{L}$ are chosen by monitors in light of the legal system in place to protect investor rightsdishonest monitors will divert up to the point where they trigger a legal response which wold force them to disgorge there ill gotten gains. Abstracting from any free-rider problem, investors will respond to opportunism with legal action only when the cost of legal action is no more than the value of the funds recovered. Thus, if monitors do divert they will divert no more than $\Gamma$ in either state, i.e, $\max \left[s_{H}, s_{L}\right] \leq \Gamma$. Thus, the legal system limits but does not block opportunism, with the strength of the limiting effect inversely proportional to $\Gamma$. For this reason, $\Gamma$ can be viewed as an index of the prevailing legal system. A high value of $\Gamma$ represents a system with poor legal enforcement where monitors can divert with impunity, while a low value of $\Gamma$ represents a legal system which deters diversion in an effective manner. We have the following three cases for the determination of $s_{H}$ and $s_{L}$. 
a. A strong legal system where $\Gamma \leq l$. In this case, $s_{H}=s_{L}=\Gamma$.

b. A moderate legal system where $l<\Gamma<h-w$. In this case, $s_{H}=\Gamma$ and $s_{L}=l$.

c. A bad legal system where $h-w \leq \Gamma$. In this case, $s_{H}=h-w$ and $s_{L}=l$.

It is obvious that an improved legal setting will reduce the level of monitor opportunism in both a board control setting and a direct shareholder control setting. However, the effect of an improved legal system on firm value and the nature of the optimal governance system is less obvious. Because monitor opportunism can have a beneficial effect on firm value in a direct shareholder control setting, legal reforms lowering $\Gamma$ can result in lower firm value. In a board control setting, legal reform unambiguously results in higher firm value. However, as the potential for diversion decreases, investors will find it worthwhile to nominate a board with a greater fraction of (possibly corrupt) insiders.

\section{Conclusion}

We model corporate governance in a world with competitive securities markets as well as markets for corporate assets. We show that the optimal governance structure for a firm that is managed by an opportunistic manager will depend on the liquidity and opacity of its assets. The governance structure will also reflect the ability of opportunistic activists and board insiders to profit from control over the firm's asset, which in turn, is a function of the legal regime in which the firm operates and the fungibility of its assets.

Our results demonstrate that governance through board control is not universally optimal. In fact, when assets are very liquid, the mere threat of liquidation together with a managerial wage that incorporates a premium above his compensation from alternative employment will be the most efficient form of governance. This form of direct shareholder control is optimal despite the absence of activist shareholders in the ownership structure. Direct shareholder control is also optimal when assets are relatively illiquid and opaque. Once again, direct shareholder control is associated with a premium built into management compensation. However, even though they do not have to actively participate in monitoring management, it is necessary for activists to be present in the ownership structure. Thus, board control is optimal only in cases where assets are moderately illiquid or not opaque. When we allow for the possibility of takeovers, we find that the premium component of management compensation increases, firm value decreases, and board control is optimal for a wide range of asset liquidity compared to the base case. A deterioration in the legal system while possibly enhancing the benefit from

direct shareholder control unambiguously erodes the desirability of board control. Thus, board control is even less desirable in situations where the legal system is weak. 


\section{Appendix}

\section{Proof of Proposition 1.}

First, we show that monitoring cannot be occurring with certainty. Monitoring with probability one eliminates all gains to the manager from attempting to appropriate cash flows. Thus, his best response to activists always monitoring is to stop attempting to appropriate cash flows. However, if the manager chooses not to divert, the activist's best response is to eschew monitoring. Thus, there cannot exist equilibria in which activists monitor the manager with probability one.

Now we show that the manager cannot be diverting with certainty. To see, this note that if the manager were diverting with probability one, activists would always monitor which would render diverting sub-optimal for the manager.

Note: The table below describes the pattern of investor ownership in this model, which is useful in deriving the proofs that follow.

\begin{tabular}{ccc}
\hline Investor type & Fraction & Number \\
\hline Activist & $\zeta N_{A}$ & $N_{A}$ \\
Passive & $1-\zeta N_{A}$ & $\frac{1-\zeta N_{A}}{\zeta}$ \\
\hline Total & 1 & $1 / \zeta$ \\
\hline
\end{tabular}

\section{Proof of Lemma 1.}

Note that if the manager is indifferent between diverting and abstaining, from (4), the present value of his expected stream of future payoffs can be written as

$$
V_{M, R}=\frac{\rho w_{r}}{r}
$$

Because each activist is indifferent between monitoring and not monitoring the manager, from (8) it follows that the probability with which the manager diverts must satisfy

$$
\theta=\frac{c}{\zeta(1-\tau)\left(r \mathcal{V}-l-\rho w_{r}\right)}
$$

From (5) and (A-2) it follows that for activists to be willing to randomize between monitoring and not monitoring the manager, it must be the case that

$$
1-\pi=\frac{\zeta f \theta}{c}
$$

Using this relationship between the probability of monitoring by activists and the probability 
of diversion by the manager, we can characterize the present value of expected cash flows to activists as

$$
V_{A, R}=\left[\frac{\zeta\left(r \mathcal{V}-\rho w_{r}\right)-c}{r_{A}}\right] N_{A}
$$

and that to passive investors as

$$
\begin{aligned}
V_{P, R} & =\frac{\left(1-\zeta N_{A}\right)}{r}\left[\left(r \mathcal{V}-\rho w_{r}\right)-\frac{c}{\zeta}(1-\pi)\right] \\
& =\frac{\left(1-\zeta N_{A}\right)}{r}\left[\left(r \mathcal{V}-\rho w_{r}\right)-\frac{c}{\zeta}\left(\frac{f}{r \mathcal{V}-l-\rho w_{r}}\right)^{\frac{1}{N_{A}}}\right]
\end{aligned}
$$

Therefore, firm value is given by the sum of the two above expressions as

$$
V_{F, R}=\left[\frac{\zeta N_{A}}{r_{A}}+\frac{1-\zeta N_{A}}{r}\right]\left(r \mathcal{V}-\rho w_{r}\right)-\frac{c N_{A}}{r_{A}}-\frac{c\left(1-\zeta N_{A}\right)}{\zeta r}\left(\frac{f}{r \mathcal{V}-l-\rho w_{r}}\right)^{\frac{1}{N_{A}}}
$$

We now proceed to solve for the stationary equilibrium. This involves solving the following program:

$$
\begin{aligned}
\max _{w_{r}, N_{A}, \zeta} V_{F, R}, & \\
\text { s.t. } \rho w_{r} & \geq \bar{v}, \\
V_{A, R}=\frac{\left[\zeta\left(r \mathcal{V}-\rho w_{r}\right)-c\right] N_{A}}{r_{A}} & \geq \zeta N_{A}, \\
\theta=\frac{c}{\zeta f}\left(\frac{f}{r \mathcal{V}-l-\rho w_{r}}\right)^{\frac{1}{N_{A}}} & \leq 1, \\
\zeta & \geq \underline{\zeta} .
\end{aligned}
$$

First, note that the objective function in (A-6) is decreasing in $w_{r}$, i.e.,

$$
\frac{\partial V_{F, R}}{\partial w_{r}}=-\rho\left[\frac{\zeta N_{A}}{r_{A}}+\frac{1-\zeta N_{A}}{r}\right]-\frac{c\left(1-\zeta N_{A}\right) \rho}{r f \zeta N_{A}}\left(\frac{f}{r \mathcal{V}-l-\rho w_{r}^{*}}\right)^{\frac{1}{N_{A}}+1}<0 .
$$

Next, note that the constraints (A-8) and (A-9) become tighter as you increase $w_{r}$, while the constraint (A-10) is unaffected. Now, it can be easily established, by means of the following argument that the constraint (A-7) binds.

Suppose that $w_{r}^{*}$ is part of the solution and (A-7) does not bind. Then the objective function can be increased by reducing $w_{r}$. Further this decrease in $w_{r}$ is feasible because constraints (A-8) and (A-9) become looser because of this reduction in $w_{r}$. This contradicts our initial supposition that $w_{r}^{*}$ maximizes firm value. Thus, the manager's reservation constraint must bind in equilibrium, i.e., in equilibrium investors will pick the manager's equilibrium compensation contract $w_{r}^{*}$ to ensure that he earns his reservation wage of $\bar{v}$ in every period. That is, the 
present value of the manager's payoff from employment with the firm, $V_{M, R}$ is given by

$$
V_{M, R}=\frac{\rho w_{r}^{*}}{r}=\frac{\bar{v}}{r}
$$

Using (A-12) to substitute for $w_{r}$ in (5) and simplifying, we obtain (10). Substituting similarly for $w_{r}$ in (8) and simplifying, we obtain (11).

\section{Proof of Lemma 2.}

First note that by Lemma 1., firm value in any stationary equilibrium with monitoring is given by (9). The first derivative of this expression with respect to the number of activists, $N_{A}$, is given by

$$
\frac{\partial V_{F, R}}{\partial N_{A}}=\zeta(r \mathcal{V}-\bar{v})\left[\frac{1}{r_{A}}-\frac{1}{r}\right]-\frac{c}{r_{A}}+\frac{c(1-\Pi)^{\frac{1}{N_{A}}}}{r \zeta}\left[\zeta+\frac{\left(1-\zeta N_{A}\right) \log (1-\Pi)}{N_{A}^{2}}\right] .
$$

In the neighborhood of $N_{A}=1$, the above derivative simplifies to

$$
\left.\frac{\partial V_{F, R}}{\partial N_{A}}\right|_{N_{A}=1}=[\zeta(r \mathcal{V}-\bar{v})-c]\left[\frac{1}{r_{A}}-\frac{1}{r}\right]-\frac{c \Pi}{r}+\frac{c(1-\Pi)(1-\zeta) \log (1-\Pi)}{r \zeta}<0
$$

From the above derivative, it is evident that the unconstrained solution will set the number of activists to its minimum possible value, $N_{A}=1$. Also note that while constraints (A-8) and (A-10) are unaffected by changes in $N_{A}$, constraint (A-9) is loosened as one decreases $N_{A}$. To see this, note that

$$
\frac{\partial \theta}{\partial N_{A}}=-\frac{c}{\zeta f N_{A}^{2}}(1-\pi) \log (1-\Pi)>0 .
$$

Therefore, we have $N_{A}^{*}=1$.

\section{Proof of Lemma 3.}

From Lemmas 1. and 2., we have the revised program as

$$
\begin{aligned}
\max _{\zeta}\left[\frac{\zeta}{r_{A}}+\frac{1-\zeta}{r}\right](r \mathcal{V}-\bar{v})-\frac{c}{r_{A}}-\frac{c(1-\zeta)}{r \zeta}\left(\frac{f}{r \mathcal{V}-l-\bar{v}}\right) & \\
\text { s.t. } \frac{\zeta(r \mathcal{V}-\bar{v})-c}{r_{A}} & \geq \zeta, \\
\theta=\frac{c}{\zeta(r \mathcal{V}-l-\bar{v})} & \leq 1, \\
\zeta & \geq \underline{\zeta} .
\end{aligned}
$$

The constraint on $\theta$ in (A-16) can never bind. To see this, note that if $\theta=1$, because

the value of the activist's payoff if she does not monitor the manager is $\frac{\zeta l}{r_{A}}$ and the activist is indifferent between monitoring and no monitoring the manager, the value of the activist's claim 
is equal to

$$
V_{A, R}=\frac{\zeta(r \mathcal{V}-\bar{v})-c}{r_{A}}=\frac{\zeta l}{r_{A}} .
$$

By Assumption 3., this implies that investing in the firm yields a negative NPV for the activist, and thus, the activist will not participate in financing the firm when $\theta=1$.

Therefore, the final program is

$$
\begin{aligned}
\max _{\zeta}\left[\frac{\zeta}{r_{A}}+\frac{1-\zeta}{r}\right](r \mathcal{V}-\bar{v})-\frac{c}{r_{A}}-\frac{c(1-\zeta)}{r \zeta}\left(\frac{f}{r \mathcal{V}-l-\bar{v}}\right) & \\
\text { s.t. } \frac{\zeta(r \mathcal{V}-\bar{v})-c}{r_{A}} & \geq \zeta, \\
\zeta & \geq \underline{\zeta} .
\end{aligned}
$$

This program implies that the optimal proportion of activists, $\zeta^{*}$ is given by the maximum of a) the minimum $\zeta$ from the constraint in $(\mathrm{A}-20)$, b) the value of $\zeta$ that just solves the constraint in (A-19), and c) the solution to the unconstrained maximand in the above program. Writing the first order condition for the unconstrained optimization problem and equating to zero, we have

$$
\begin{aligned}
& \qquad \frac{\partial V_{F, R}}{\partial \zeta}=(r \mathcal{V}-\bar{v})\left(\frac{1}{r_{A}}-\frac{1}{r}\right)+\frac{c}{r}\left(\frac{f}{r \mathcal{V}-l-\bar{v}}\right) \frac{1}{\zeta^{2}}=0, \\
& \text { which implies that the unconstrained solution solves } \zeta^{2}=\frac{\frac{c f}{(r \mathcal{V}-l-\bar{v})}}{\left(1-\frac{r}{r_{A}}\right)(r \mathcal{V}-\bar{v})} .
\end{aligned}
$$

Combining the values from a), b) and c) above, we arrive at the expression in (13).

\section{Proof of Proposition 2.}

Let $w_{e}$ be the manager's wage in equilibrium, and $w_{o}$ that off the equilibrium path in randomization. Note that the first time the manager or the activists deviate, one enters a subgame that is virtually identical to the stationary (randomizing) equilibrium described above. Thus, we first have to solve for the optimal $w_{o}, \theta_{o}$ and $\pi_{o}$, taking $\zeta$ and $N_{A}$ as fixed. Then, taking this solution, we solve for the optimal $\zeta$ and $N_{A}$ in the supergame.

Consider the constraints on the governance structure that apply in the subgame that begins with the first diversion by the manager or deviation from the strategy of not monitoring by activists. First, from the activists' point of view, liquidation is inferior to letting the manager divert every period, i.e,

$$
1-\lambda \leq \frac{l}{r_{A}}
$$

Note that the above condition also implies that liquidation is inferior from the passive investors' point of view, as

$$
1-\lambda \leq \frac{l}{r_{A}} \leq \frac{l}{r}
$$


Second, randomized monitoring is preferred to letting the manager divert in every future period, which implies

$$
\frac{\left[\zeta\left(r \mathcal{V}-\rho w_{o}\right)-c\right] N_{A}}{r_{A}} \geq \frac{\zeta N_{A} l}{r_{A}} .
$$

Third, the manager must be paid at least his reservation off the equilibrium path, i.e.,

$$
\rho w_{o} \geq \bar{v}
$$

Finally, the probabilities of monitoring and diversion must be well-behaved, i.e,

$$
1-\Pi_{o}=\frac{f}{r \mathcal{V}-l-\rho w_{o}} \leq 1
$$

and

$$
\theta_{o}=\frac{c}{\zeta f}\left(\frac{f}{r \mathcal{V}-l-\rho w_{o}}\right)^{\frac{1}{N_{A}}} \leq 1 .
$$

Note that this problem is virtually identical to the one we solved earlier. The only difference is on the right hand side of the NPV conditions for activists, i.e., the right hand side of (A-8) versus the right hand side of (A-22), and this change has no effect on the argument for setting the equilibrium wage. Consequently it has to be the case that the manager's off-equilibrium reservation constraint must bind in the subgame, i.e., $\rho w_{o}=\bar{v}$.

Coming to the supergame in equilibrium, we need the following conditions to be satisfied. First, we need that activists do not deviate (and monitor randomly), which implies

$$
\frac{\zeta N_{A}\left(r \mathcal{V}-\rho w_{e}\right)}{r_{A}} \geq \frac{[\zeta(r \mathcal{V}-\bar{v})-c] N_{A}}{r_{A}}
$$

Further, because

$$
\frac{\zeta N_{A}\left(r \mathcal{V}-\rho w_{e}\right)}{r} \geq \frac{\zeta N_{A}\left(r \mathcal{V}-\rho w_{e}\right)}{r_{A}} \geq \frac{[\zeta(r \mathcal{V}-\bar{v})-c] N_{A}}{r_{A}} \geq \frac{\zeta N_{A} l}{r_{A}} \geq \zeta N_{A}(1-\lambda)
$$

it follows that

$$
\frac{\left(1-\zeta N_{A}\right)\left(r \mathcal{V}-\rho w_{e}\right)}{r} \geq\left(1-\zeta N_{A}\right)(1-\lambda),
$$

which means that passive investors do not deviate, and liquidate.

Next, the manager must not deviate (and divert). Note that if the manager decides to deviate from the equilibrium strategy and divert, he incurs a cost $f$, and with probability $\rho$ captures the cash flow of $h-l$ in the current period. However, with probability $\rho$ the present value of his future compensation is $\frac{\bar{v}}{r}$. With probability $1-\rho$ he receives zero in this period, and $\rho w_{e}$ in each future period. Thus, the manager's expected payoff if he deviates from his equilibrium strategy and diverts is

$$
\rho(h-l)-f+\rho\left(\frac{\bar{v}}{r}\right)+(1-\rho) \frac{\rho w_{e}}{r} .
$$


If the manager does not divert, his payoff is

$$
\rho w_{e} \frac{(1+r)}{r}
$$

Following the equilibrium strategy is incentive compatible for the manager if his payoff from not deviating is at least as large as his payoff from deviating. That is,

$$
\rho w_{e} \geq \frac{r(r \mathcal{V}-l-f)+\rho \bar{v}}{r+\rho} \geq \bar{v} .
$$

Noting that the aggregate value to investors is decreasing in $w_{e}$ and the constraint $(\mathrm{A}-26)$ is loosened by lowering $w_{e}$, the manager's wage must be set at its minimum possible value in equilibrium, i.e.,

$$
\rho w_{e}^{*}=\frac{r(r \mathcal{V}-l-f)+\rho \bar{v}}{r+\rho} .
$$

Following from the above, the excess payment to the manager over and above his reservation wage is an "efficiency wage", and the present value of all such efficiency wages is

$$
\mathcal{B}=\frac{\rho w_{e}^{*}-\bar{v}}{r}=\frac{r \mathcal{V}-\bar{v}-l-f}{r+\rho} .
$$

Substituting this value for $\rho w_{e}^{*}$ in terms of $\mathcal{B}$ into the investors' objective function, and collecting all the constraints, we have the following program to solve:

$$
\begin{aligned}
\max _{\zeta, N_{A}} V_{F, E} & =\left[\frac{\zeta N_{A}}{r_{A}}+\frac{1-\zeta N_{A}}{r}\right][r(\mathcal{V}-\mathcal{B})-\bar{v}], \\
\text { s.t. } \zeta & \leq \frac{c}{r \mathcal{B}}, \\
\zeta & \geq \frac{c}{r \mathcal{V}-l-\bar{v}}, \\
\zeta & \geq \frac{c}{(r \mathcal{V}-l-\bar{v})\left(\frac{f}{r \mathcal{V}-l-\bar{v}}\right)^{\frac{N_{A}-1}{N_{A}}}} \\
\zeta & \geq \underline{\zeta} \\
1-\lambda & \leq \frac{l}{r_{A}}
\end{aligned}
$$

In the above program, the maximand is simply firm value with the equilibrium wage substituted in terms of $\mathcal{B}$. The first constraint is simply condition (A-26) with the equilibrium wage substituted in. The second constraint is (A-22) with the off-equilibrium wage substituted in. The next constraint restricts the probability of diversion in the subgame, $\theta$, to be no greater than one, given the optimal choice of $\zeta$ and $N_{A}$ in the supergame. The fourth constraint is the restriction on the minimum stake per activist. The last constraint ensures that liquidation is suboptimal even off the equilibrium path.

Because $\frac{f}{r \mathcal{V}-l-\bar{v}}<1$ by Assumption 2., the right hand side of (A-35) is larger than the right 
hand side of (A-34), ensuring that (A-34) is redundant. First, we characterize the solution to the problem ignoring constraint (A-33). Once we solve the problem, we show that this constraint is always satisfied by the optimal solution to the simplified problem.

Note that $V_{F, E}$ is a decreasing function of $N_{A}$ as shown by the following partial derivative:

$$
\frac{\partial V_{F, E}}{\partial N_{A}}=\zeta\left(\frac{1}{r_{A}}-\frac{1}{r}\right)[r(\mathcal{V}-\mathcal{B})-\bar{v}]<0
$$

Further, all the constraints are unaffected by changing $N_{A}$. Thus, in any solution to the simplified problem the optimal number of activists, $N_{A}^{*}=1$.

Next note that $V_{F, E}$ is decreasing in $\zeta$, which implies that $\zeta$ will be set equal to its minimum possible value in the solution, i.e., because $N_{A}^{*}=1$, from (A-35) and (A-36) at

$$
\zeta^{*}=\max \left[\underline{\zeta}, \frac{c}{r \mathcal{V}-l-\bar{v}}\right]
$$

Now we show that the above solution satisfies constraint (A-33). Note that

$$
\frac{c}{r \mathcal{B}}=\frac{c}{r \mathcal{V}-l-f-\bar{v}}\left(\frac{r+\rho}{r}\right) \geq \frac{c}{r \mathcal{V}-l-f-\bar{v}} \geq \frac{c}{r \mathcal{V}-l-\bar{v}}
$$

Thus, by condition (16) and the definition of $\zeta^{*}$ above, it follows that (A-33) is non-binding.

To complete the proof, note that investors (both activists and passive investors) have to be willing to capitalize the firm. They will be willing to do so as long as their investment of $\$ 1$ has a non-negative NPV. A sufficient condition for this is

$$
\frac{r \mathcal{V}-\rho w_{e}^{*}}{r_{A}}=\frac{r(\mathcal{V}-\mathcal{B})-\bar{v}}{r_{A}} \geq 1
$$

This is the condition in (15).

\section{Proof of Proposition 3.}

In such equilibria, if the manager is caught diverting, investors liquidate the firm. This does not need the presence of activists (and attendant monitoring costs), and in all such equilibria, firm value is maximized by an ownership structure that features only passive investors, i.e, $N_{A}=0, \zeta=0$.

We assume that if the manager diverts, investors switch to believing that the manager will divert in every future period. If the manager diverts, given the investors' beliefs regarding his future actions, activists have two alternatives-they can choose to continue to remain invested in the firm, or they can liquidate the firm. If they continue to remain invested, they can at best expect to earn $l$ in every future period and thus the value of their claims is at most $\frac{l}{r}$. If investors choose to liquidate the firm, they receive a payoff of $1-\lambda$. Thus, so long as (22) is satisfied, liquidating the firm after the manager diverts for the first time is optimal from the 
investor's perspective.

Now we proceed to demonstrate that the manager receives $\mathcal{B}+\frac{\bar{v}}{r}$ as compensation in equilibrium. To ensure that the manager chooses to stay employed with the fund, he must receive at least his reservation wage in every period, i.e., $\mathcal{B} \geq 0$.

As in the previous non-stationary equilibrium, following the equilibrium strategy is incentive compatible for the manager if his payoff from not deviating is at least as large as his payoff from deviating, after which the firm is liquidated and he earns his reservation wage of $\bar{v}$ in every future period. Therefore the equilibrium wage again satisfies

$$
\rho w_{e}^{*}=\bar{v}+r \mathcal{B}
$$

To complete the proof, note that investors as a group have to be willing to capitalize the firm. They will be willing to do so as long as their combined investment of $\$ 1$ has a non-negative NPV, or

$$
\mathcal{V}-\frac{\rho w_{e}^{*}}{r} \geq 1
$$

Next, investors in equilibrium should not deviate and liquidate the firm.

$$
\mathcal{V}-\frac{\rho w_{e}^{*}}{r} \geq 1-\lambda
$$

Note that (A-42) implies (A-43).

Condition (23) is then simply (A-42), upon substitution from (A-41).

\section{Proof of Proposition 4.}

First note that when (26) is satisfied neither of the two non-stationary equilibria with direct shareholder control can exist. Thus, to prove that board control dominates direct shareholder control we only need to establish that board control generates higher firm value than direct control when both the manager and the activists are randomizing. To see this note that, if $\Delta$ represents the value of the firm under board control less the value of the firm under the activist and manager randomization

$$
\begin{aligned}
\Delta & =\frac{1}{r}(r \mathcal{V}-\bar{v}-c)-\left[\frac{\zeta}{r_{A}}+\frac{1-\zeta}{r}\right](r \mathcal{V}-\bar{v})+\frac{c}{r_{A}}+\frac{c(1-\zeta)}{r \zeta}\left(\frac{f}{r \mathcal{V}-l-\bar{v}}\right), \\
& =[\zeta(r \mathcal{V}-\bar{v})-c]\left[\frac{1}{r}-\frac{1}{r_{A}}\right]+\frac{c(1-\zeta)(1-\Pi)}{r \zeta}>0 .
\end{aligned}
$$

Now we establish that board control and activist ownership are sub-optimal when the cost of liquidating the firm's assets $(\lambda)$ and the manager's efficiency wage $\mathcal{B}+\frac{\bar{v}}{r}$ are relatively low. To see this note that when the cost of liquidating assets is relatively low, the non-stationary equilibrium with random monitoring activists following the first diversion by the manager is not feasible. Thus, to prove the claim we demonstrate that firm value in non-stationary equilibria 
with liquidation following managerial diversion is higher than firm value under either board control or in the stationary equilibria where the manager and activist randomize. First note that by inspection it is obvious that

$$
\frac{1}{r}(r \mathcal{V}-\bar{v}-r \mathcal{B}) \geq\left[\frac{\zeta}{r_{A}}+\frac{1-\zeta}{r}\right](r \mathcal{V}-\bar{v})-\frac{c}{r_{A}}-\frac{c(1-\zeta)}{r \zeta}\left(\frac{f}{r \mathcal{V}-l-\bar{v}}\right)
$$

for sufficiently low $\mathcal{B}$. Next note that

$$
\frac{1}{r}(r \mathcal{V}-\bar{v}-r \mathcal{B})-\frac{1}{r}(r \mathcal{V}-\bar{v}-c)
$$

is positive for sufficiently small $\mathcal{B}$. Further, when $\mathcal{B}$ and $\lambda$ are sufficiently small, both the conditions for existence of the non-stationary equilibria with liquidation off the equilibrium path, (22) and (23) are satisfied. This establishes part $b$ of the Proposition.

Finally, we establish that activist ownership is optimal when the cost of liquidating the firm's assets $(\lambda)$ is relatively high but the manager's efficiency wage $\mathcal{B}+\frac{\bar{v}}{r}$ and the return premium $r_{A}-r$ required by activists are relatively low. To see this note that when the cost of liquidating assets is relatively high, the non-stationary equilibrium with liquidation following the first diversion by the manager is not feasible. Thus, to prove the claim we demonstrate that firm value in non-stationary equilibria with random monitoring following managerial diversion is higher than firm value under board control and the non-stationary equilibria are feasible. To see that firm value is higher in the non stationary equilibria with monitoring off the equilibrium path note that

$$
\left[\frac{\zeta}{r_{A}}+\frac{1-\zeta}{r}\right](r \mathcal{V}-\bar{v}-r \mathcal{B})-\frac{1}{r}(r \mathcal{V}-\bar{v}-c)
$$

is positive for sufficiently small $\mathcal{B}$ and $r_{A}-r$. Further, it is obvious that for sufficiently small $\mathcal{B}$ and $r_{A}-r$ the two conditions for the existence of non-stationary equilibria with randomization off the equilibrium path (15) and (16) are satisfied.

\section{Proof of Lemma 4.}

This result follows directly by noting that firm value when both the manager and activists are randomizing is always less than firm value when only the activists are randomizing so as to just deter the manager from diverting. Note that for a given number of activists, $N_{A}$, we have

$$
\begin{aligned}
& V_{F}\left(0, \Pi, N_{A}, \hat{\zeta}\left(N_{A}, 0\right)\right)-V_{F}\left(\theta, \Pi, N_{A}, \hat{\zeta}\left(N_{A}, \theta\right)\right) \\
= & {\left[\hat{\zeta}\left(N_{A}, \theta\right)-\hat{\zeta}\left(N_{A}, 0\right)\right]\left[N_{A}\left(\frac{1}{r}-\frac{1}{r_{A}}\right)+\frac{\delta(1-\Pi)(r \mathcal{V}-\rho w)}{r \hat{\zeta}\left(N_{A}, \theta\right)}\right]>0 . }
\end{aligned}
$$

This result follows from direct substitution of firm values from (42) and (43) and some simplification.

Note that we have used above the fact that it is always possible to deter the manager from 
diverting for a lower per capital ownership stake for the activists. This follows because $\hat{\zeta}\left(N_{A}, \theta\right)$ is increasing in $\theta$.

\section{Proof of Proposition 5.}

Given our earlier result in Lemma 4., it is sufficient to establish that firm value under multiple activists when activists are monitoring randomly and the manager does not steal is higher than firm value under the following two outcomes:

a. Firm value under a single activist who monitors with sufficiently high probability to leave the manager indifferent to diverting.

b. Firm value under a single activist who always monitors deterministically.

To establish a., we only require that $V_{F}\left(0, \Pi, N_{A}, \hat{\zeta}\left(N_{A}, 0\right)\right)$ increase in $N_{A}$. Using (42), we have

$$
\begin{aligned}
\frac{\partial V_{F}\left(0, \Pi, N_{A}, \hat{\zeta}\left(N_{A}, 0\right)\right)}{\partial N_{A}} & =-(r \mathcal{V}-\rho w) \frac{\partial N_{A} \hat{\zeta}\left(N_{A}, 0\right)}{\partial N_{A}}\left[(1-\delta)\left(\frac{1}{r}-\frac{1}{r_{A}}\right)+\frac{\delta(1-\Pi)}{r}\right]-\frac{c}{r_{A}}, \\
\text { where } \frac{\partial N_{A} \hat{\zeta}\left(N_{A}, 0\right)}{\partial N_{A}} & =-\frac{c}{\delta(r \mathcal{V}-\rho w)(1-\Pi)^{\frac{N_{A}-1}{N_{A}}}}\left[1-\frac{1}{N_{A}} \log (1-\Pi)\right] . \quad \quad(\mathrm{A}-48)
\end{aligned}
$$

In fact, we can write a sufficiency condition for $V_{F}\left(0, \Pi, N_{A}, \hat{\zeta}\left(N_{A}, 0\right)\right)$ to increase in $N_{A}$ as follows:

$$
[1-\log (1-\Pi)]\left[\left(\frac{1-\delta}{\delta}\right)\left(\frac{r_{A}}{r}-1\right)+(1-\Pi) \frac{r_{A}}{r}\right]>1 .
$$

We next establish b. of the above proof. First note that

$$
\frac{\partial V_{F}(0,1,1, \zeta)}{\partial \zeta}=(1-\delta)(r \mathcal{V}-\rho w)\left(\frac{1}{r_{A}}-\frac{1}{r}\right)<0
$$

Thus, to establish b. it is sufficient to establish conditions under which

$$
V_{F}\left(0, \Pi, N_{A}, \hat{\zeta}\left(N_{A}, 0\right)\right)-V_{F}(0,1,1, \underline{\zeta})>0
$$

Following from (40) and (42), we have

$$
\begin{aligned}
& V_{F}\left(0, \Pi, N_{A}, \hat{\zeta}\left(N_{A}, 0\right)\right)-V_{F}(0,1,1, \underline{\zeta}) \\
= & (r \mathcal{V}-\rho w)\left[\frac{\delta(1-\Pi)\left(1-N_{A} \hat{\zeta}\left(N_{A}, 0\right)\right)}{r}-\left(\frac{1}{r}-\frac{1}{r_{A}}\right)(1-\delta)\left(N_{A} \hat{\zeta}\left(N_{A}, 0\right)-\underline{\zeta}\right)\right]-\frac{c\left(N_{A}-1\right)}{r_{A}},
\end{aligned}
$$


and a sufficient condition for the same to be non-negative is

$$
c \leq(r \mathcal{V}-\rho w)\left[\frac{\delta r_{A}(1-\Pi)\left(1-N_{A} \hat{\zeta}\left(N_{A}, 0\right)\right)}{r\left(N_{A}-1\right)}-\left(\frac{r_{A}}{r}-1\right)\left(\frac{1-\delta}{N_{A}-1}\right)\left(N_{A} \hat{\zeta}\left(N_{A}, 0\right)-\underline{\zeta}\right)\right] .
$$

Therefore, we have proved that if (A-49) and (A-52) are satisfied, along with mild technical conditions that the manager be paid his reservation wage, there is an equilibrium where the optimal number of activists is $N_{A}^{*}$ satisfying

$$
\hat{\zeta}\left(N_{A}^{*}, 0\right)=\underline{\zeta} .
$$

\section{Proof of Proposition 6.}

We first provide a general proof for the first part of the proposition. Let the random nature of dishonesty among inside directors be characterized by the cumulative distribution function $F(a, t)$, and its associated (continuous) probability density function $f(a, t)$. Note that in these functions, $t$ is a variable representing a point within the support of the probability distribution, while $a$ is a parameter that characterizes the entire family of the distribution function.

Following from (46), we write firm value as

$$
V_{B}=[r \mathcal{V}-\bar{v}]-\delta[r \mathcal{V}-\bar{v}]\left[1-F\left(a, \frac{1}{2 \mu}\right)\right]-n\left[(1-\mu) b_{O}+\mu b_{I}\right]
$$

As described in the text, the optimal fraction of insiders $\mu^{*}$ - if an interior solution in $(0.5,1)$ exists - is determined as the solution to

$$
\frac{\partial V_{B}}{\partial \mu}=0
$$

and when substituted into the firm value equation above, yields the optimal firm value $V_{B}^{*}$.

We wish to examine how optimal firm value, $V_{B}^{*}$ varies with $a$, i.e, we wish to evaluate the derivative

$$
\frac{\partial V_{B}^{*}}{\partial a}=\left.\frac{\partial V_{B}}{\partial a}\right|_{\mu=\mu^{*}}+\left(\frac{\partial V_{B}}{\partial \mu}\right)\left(\frac{\partial \mu^{*}}{\partial a}\right)
$$

By an application of the envelope theorem, the above derivative reduces to

$$
\frac{\partial V_{B}^{*}}{\partial a}=\left.\frac{\partial V_{B}}{\partial a}\right|_{\mu=\mu^{*}}=\delta[r \mathcal{V}-\bar{v}] \frac{\partial F\left(a, \frac{1}{2 \mu^{*}}\right)}{\partial a}
$$

Therefore, we have

$$
\operatorname{sgn}\left(\frac{\partial V_{B}^{*}}{\partial a}\right)=\operatorname{sgn}\left(\frac{\partial F(., .)}{\partial a}\right)
$$

If $F(a, t)$ is increasing in $a, V_{B}^{*}$ is increasing in $a$. In this case, a higher value of $a$ represents 
more honesty in the sense of first-order stochastic dominance, and therefore $V_{B}^{*}$ is increasing in honesty. In the opposite case, if $F(a, t)$ is decreasing in $a, V_{B}^{*}$ is decreasing in $a$. The interpretation now is that a lower value of $a$ represents more honesty in the sense of first-order stochastic dominance. Once again, $V_{B}^{*}$ is increasing in honesty. Therefore, we have proved the first part of the proposition.

To prove the second part of the proposition, we need only show that there is at least one valid probability distribution function for which the likelihood of insider diversion increases with an overall increase in honesty. We show that this assertion is true when $\eta$ follows a Pareto distribution.

Substituting from (48) into (47) of the text, and simplifying, we have the optimal proportion of insiders as

$$
\mu^{*}=\frac{n\left(b_{O}-b_{I}\right)\left(1-a^{2}\right)}{8 \delta(r \mathcal{V}-\bar{v}) a^{2}} .
$$

Let the likelihood of diversion by insiders, at the optimal fraction of insiders on the board be represented by $\mathcal{L}$, where

$$
\mathcal{L}=1-F\left(\frac{1}{2 \mu^{*}}\right)=\frac{a^{2}\left(4 \mu^{* 2}-1\right)}{1-a^{2}}
$$

Given that

$$
\frac{\partial \mu^{*}}{\partial a}=\frac{-n\left(b_{O}-b_{I}\right)}{4 \delta(r \mathcal{V}-\bar{v}) a^{3}}<0
$$

it follows that

$$
\frac{\partial \mathcal{L}}{\partial a}=-\frac{n^{2}\left(b_{O}-b_{I}\right)^{2}}{8 \delta^{2}(r \mathcal{V}-\bar{v})^{2} a^{3}}-\frac{2 a}{\left(1-a^{2}\right)^{2}}<0 .
$$

In the case of a Pareto distribution, as a increases, dishonesty increases in the sense of first order stochastic dominance of the distribution of $\eta$. Conversely, as a decreases, honesty increases. In other words, in this case, as honesty increases, the likelihood of diversion increases. 


\begin{tabular}{|c|c|c|}
\hline Variable & 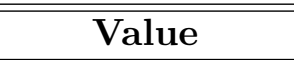 & Description \\
\hline \multicolumn{3}{|c|}{ Basic parameters for all figures } \\
\hline $\bar{X}$ & $X \in\{0.70,0.03\}$ & Random cash flow from investment \\
\hline$\rho$ & 0.60 & Probability of high state \\
\hline$r$ & 0.24 & Risk-free rate per period \\
\hline$r_{A}$ & 0.28 & Discount rate for activists \\
\hline $\bar{v}$ & 0.10 & Per-period reservation wage to manager in labor market \\
\hline$\zeta$ & 0.15 & Minimum shareholding per activist \\
\hline $\bar{f}$ & 0.20 & Ex-ante cost of diversion to manager \\
\hline \multicolumn{3}{|l|}{ Figure 1} \\
\hline$c$ & 0.05 & Cost of activist monitoring \\
\hline \multicolumn{3}{|l|}{ Figure 2} \\
\hline$c$ & 0.0275 & Cost of activist monitoring \\
\hline \multicolumn{3}{|l|}{ Figure 3} \\
\hline$c$ & 0.0275 & Cost of activist monitoring \\
\hline$\kappa$ & 0.25 & Probability of takeover \\
\hline$Z$ & 1.574 & Takeover offer \\
\hline \multicolumn{3}{|l|}{ Figure 4} \\
\hline$c$ & 0.05 & Cost of activist monitoring \\
\hline$Z$ & 1.462 & Takeover offer \\
\hline \multicolumn{3}{|c|}{ Figures 5 through 10} \\
\hline$\delta$ & 0.20 & Fraction of cash flows lost due to activist diversion \\
\hline$\alpha$ & 0.80 & Fraction of activist stealing not dissipated \\
\hline$c$ & 0.0136 & Cost of activist monitoring \\
\hline \multicolumn{3}{|c|}{ Figures 7 through 10} \\
\hline$n$ & 10 & Number of directors on board \\
\hline$b_{O}$ & 0.0014 & Cost per outside director \\
\hline$b_{I}$ & 0.0007 & Cost per inside director \\
\hline \multicolumn{3}{|l|}{ Figure 11} \\
\hline$r_{A}$ & 0.2401 & Discount rate for activists \\
\hline
\end{tabular}

Table 1: Parameter values for numerical analysis 


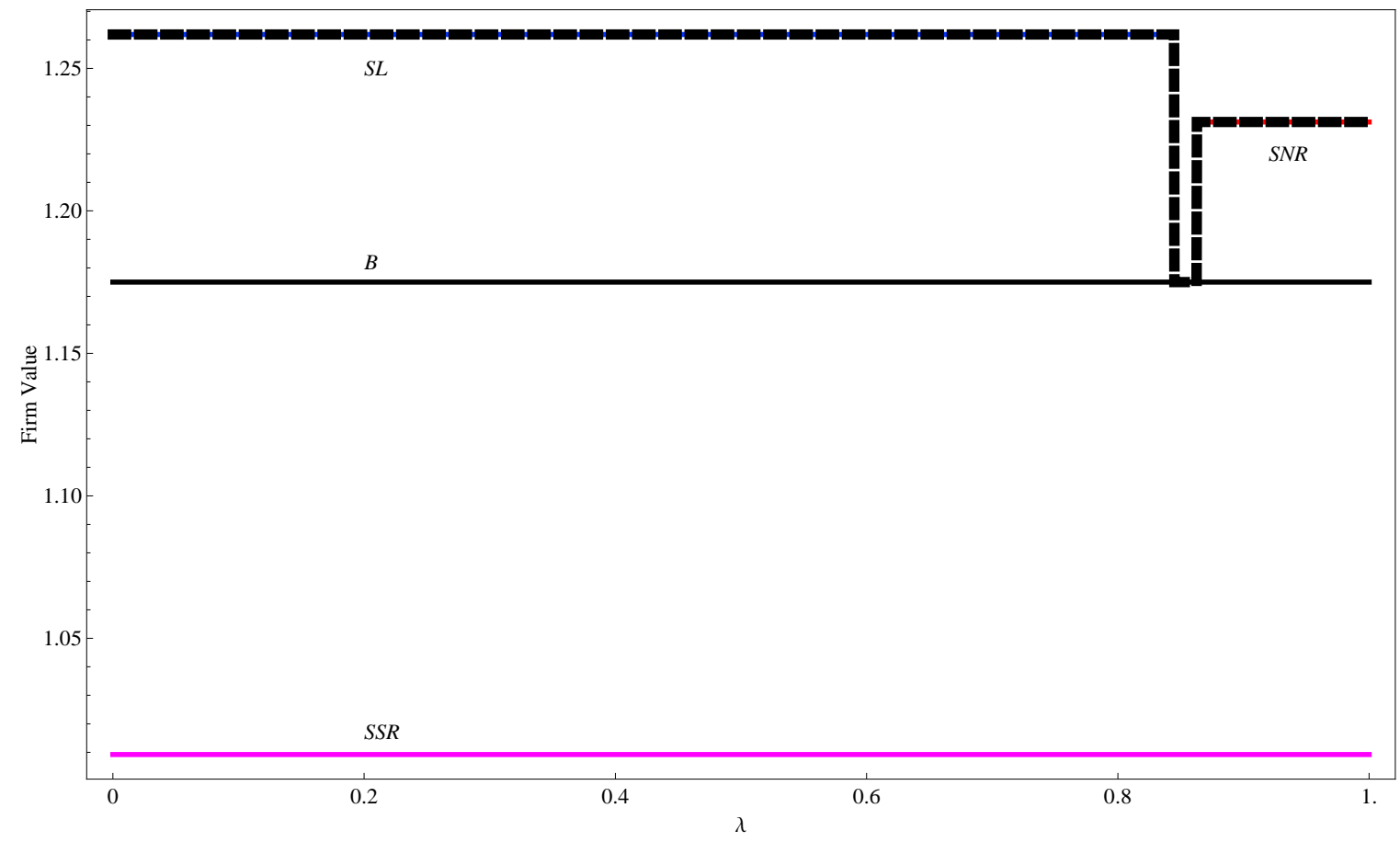

Figure 1: Investor vs board monitoring as a function of asset liquidity

In this figure, we plot firm value with investor monitoring as a function of the liquidation discount, $\lambda$, compared with that in the presence of an honest board. Here, "SSR" refers to the stationary shareholder monitoring equilibrium where activist shareholders and the manager randomize over monitoring and stealing respectively. "SL" represents the non-stationary equilibrium without activist shareholders, where upon the first instance of diversion, passive shareholders liquidate the firm. "SNR" refers to the non-stationary equilibrium with activist shareholders, where upon the first instance of diversion, active shareholders and the manager revert to randomized monitoring and stealing. "B" refers to the stationary equilibrium, featuring monitoring by an honest board.

It can be observed that as the liquidity of firm assets increases, the optimal choice of governance mechanisms changes. At very low values of $\lambda$, i.e, when assets are very liquid, the investors' threat to liquidate assets and effectively fire the manager is credible, and dominates the board. At the other end of the spectrum, with very illiquid assets, activists have to threaten to start randomly monitoring in case the manager diverts cash flows. Again, in this case, investor monitoring dominates the board. In the intermediate range, monitoring by a board is optimal. Note that the stationary equilibrium with random monitoring and stealing exists across the entire range of liquidity; however, it is always dominated. 


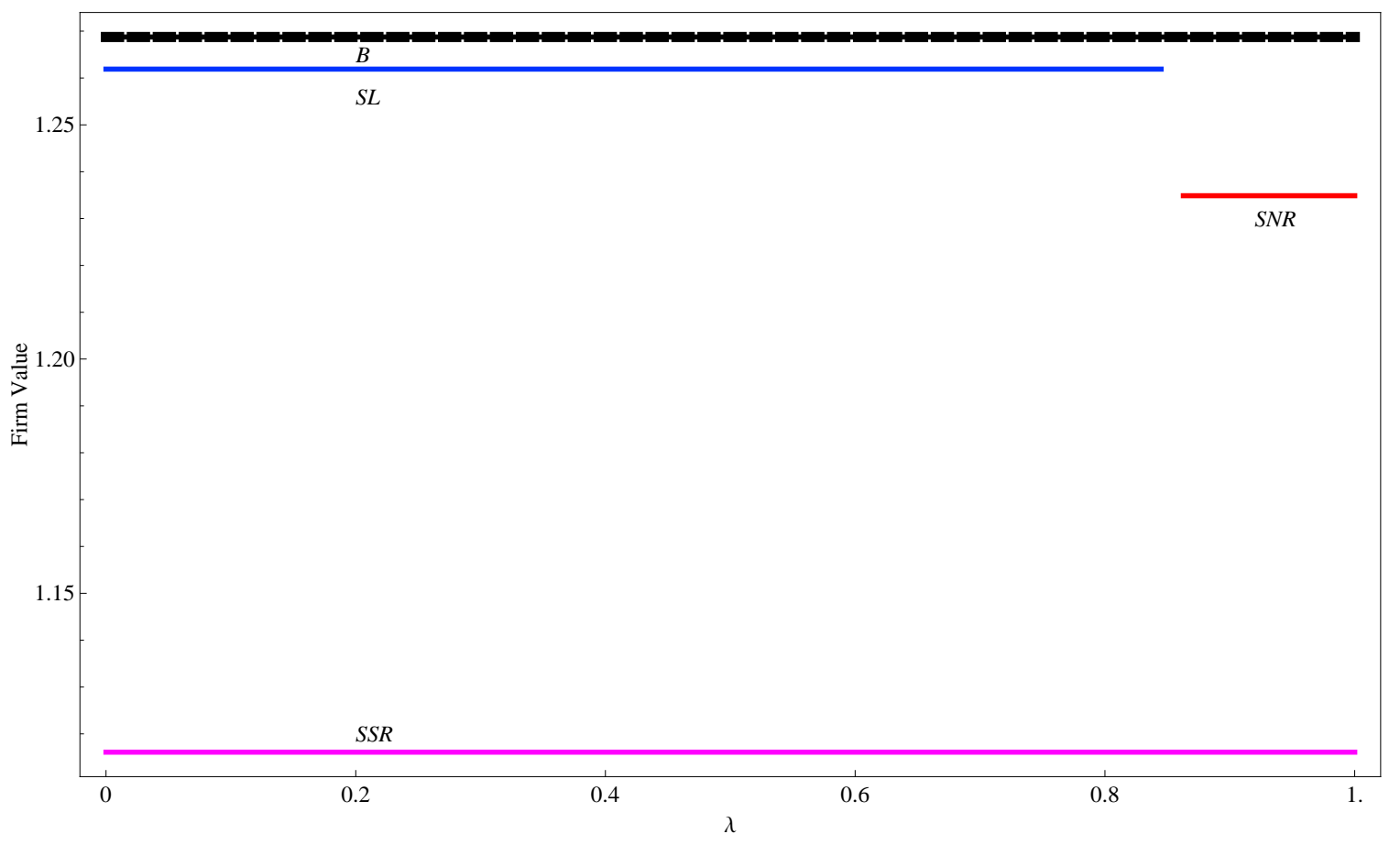

Figure 2: Investor vs board monitoring as a function of asset liquidity

This figure is identical to Figure 1 in all aspects, except the opacity of assets. In particular, the cost of stealing to the manager is still $f=0.20$; however, we now have a lower value of $c=0.0275$, as opposed to $c=0.05$ in Figure 1. In this case, board monitoring dominates monitoring by investors across the entire spectrum of asset liquidity. 


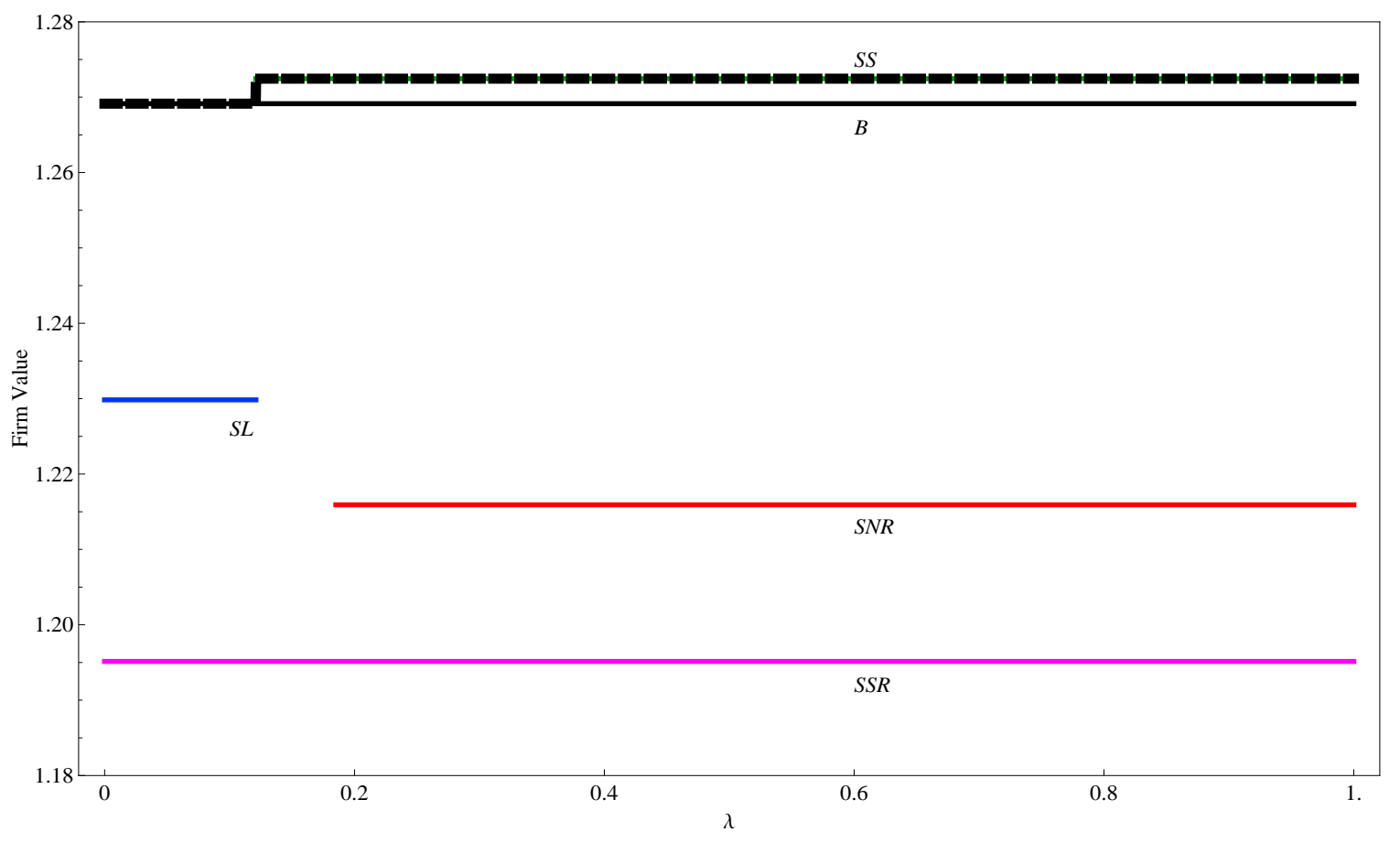

Figure 3: Effect of a takeover threat: A new non-stationary equilibrium with diversion

In this figure, "SSR", "SL", "SNR", and "B" continue to have the same meaning as in Figures 1 and 2, while "SS" is the new equilibrium where a high enough probability of a takeover (here $\kappa=0.25$ ) supports a governance structure where the manager does not divert on the equilibrium path, but subsequent to the first diversion, his wage is set to zero and he diverts in every future period. In this case, this new governance structure, wherever feasible, dominates both board governance and other forms of direct shareholder control. 


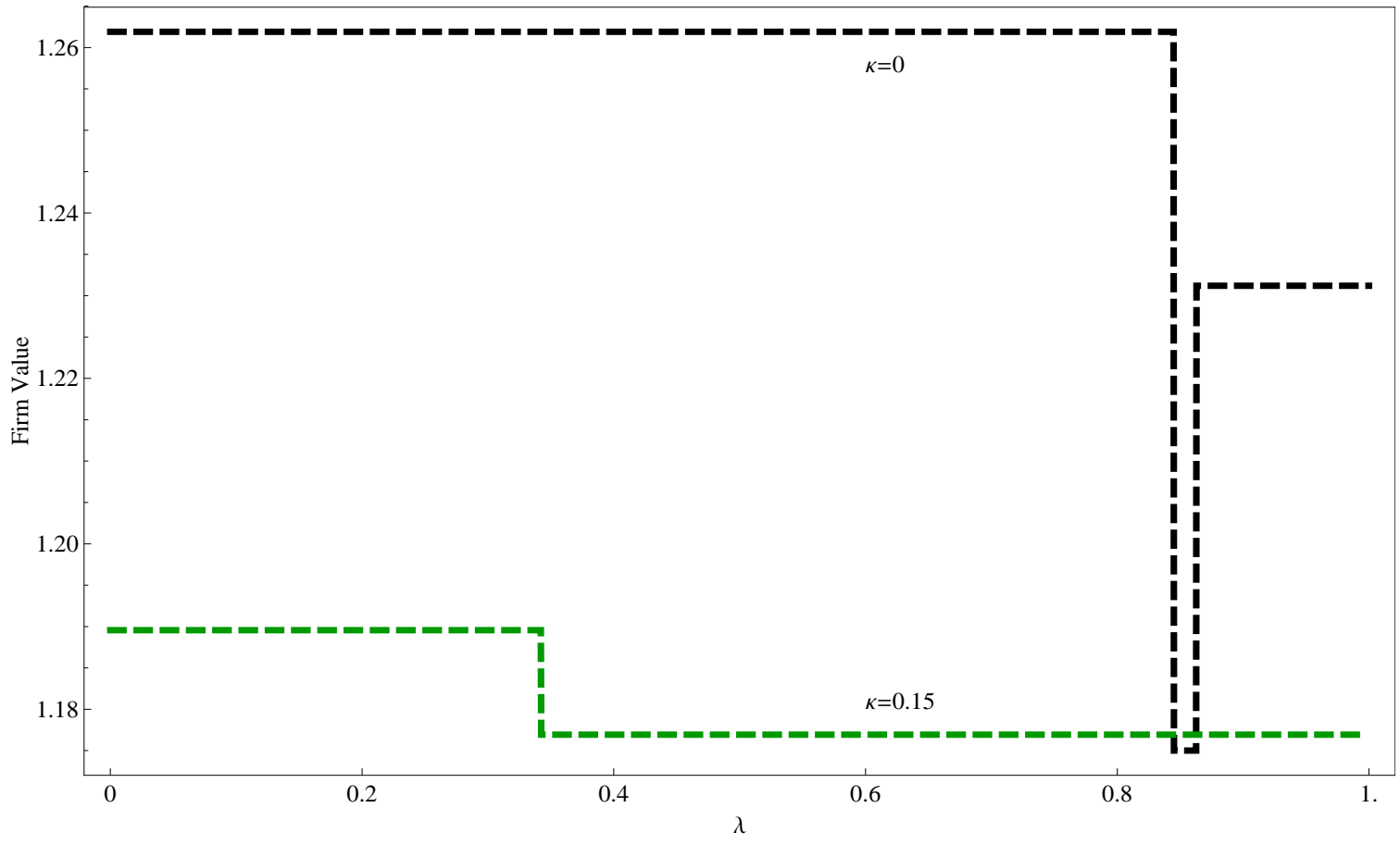

Figure 4: Effect of a takeover threat: Firm valuation and the balance of governance

In this figure, we compare firm value with and without a takeover threat. We see that, in the absence of a takeover threat, direct shareholder control is optimal at both end of the liquidity spectrum and board control is optimal for intermediate levels of liquidity. However, when there is a probability of a takeover $(\kappa=0.15)$, firm value under board control rises, while that conditional on shareholder control falls at both extremes. This results in a decline in firm value, as well as a change in the balance between direct shareholder control and board control. 


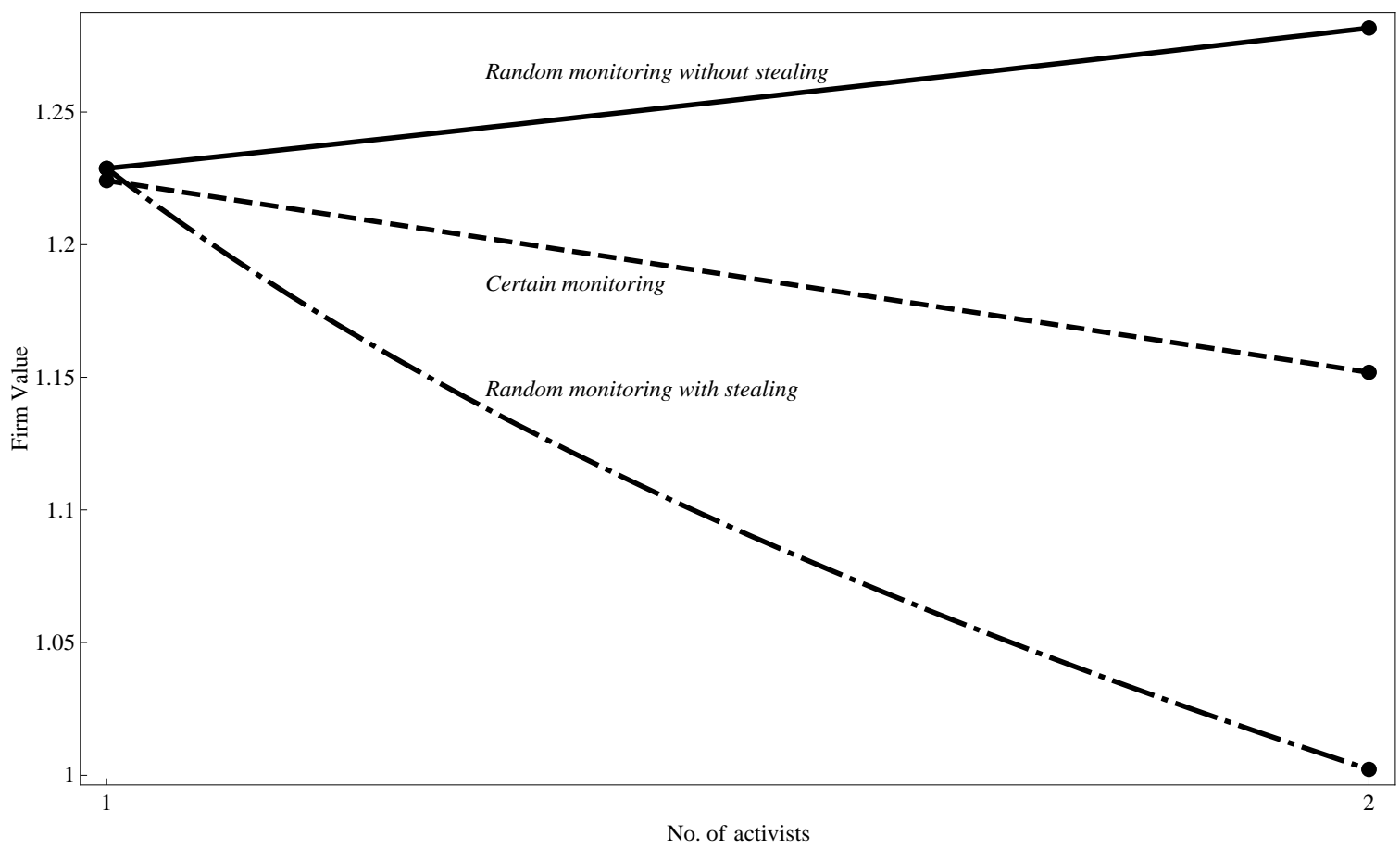

Figure 5: Firm value as a function of number of activists

This figure plots firm value in the presence of opportunistic activists under each of the three possible configurations. Under certain monitoring, there is no managerial diversion; however, increasing the number of activists decreases firm value, as monitoring by multiple activists is wasteful. Under random monitoring with stealing, there is wasteful monitoring, as well as managerial diversion, leading to a decrease in firm value as the number of activists increases. In sharp contrast to these cases, under random monitoring that deters stealing, firm value increases with the number of activists, as each activist now needs to hold a smaller share of the firm, which reduces the fraction of firm value accruing to activists, while simultaneously preventing managerial stealing. 


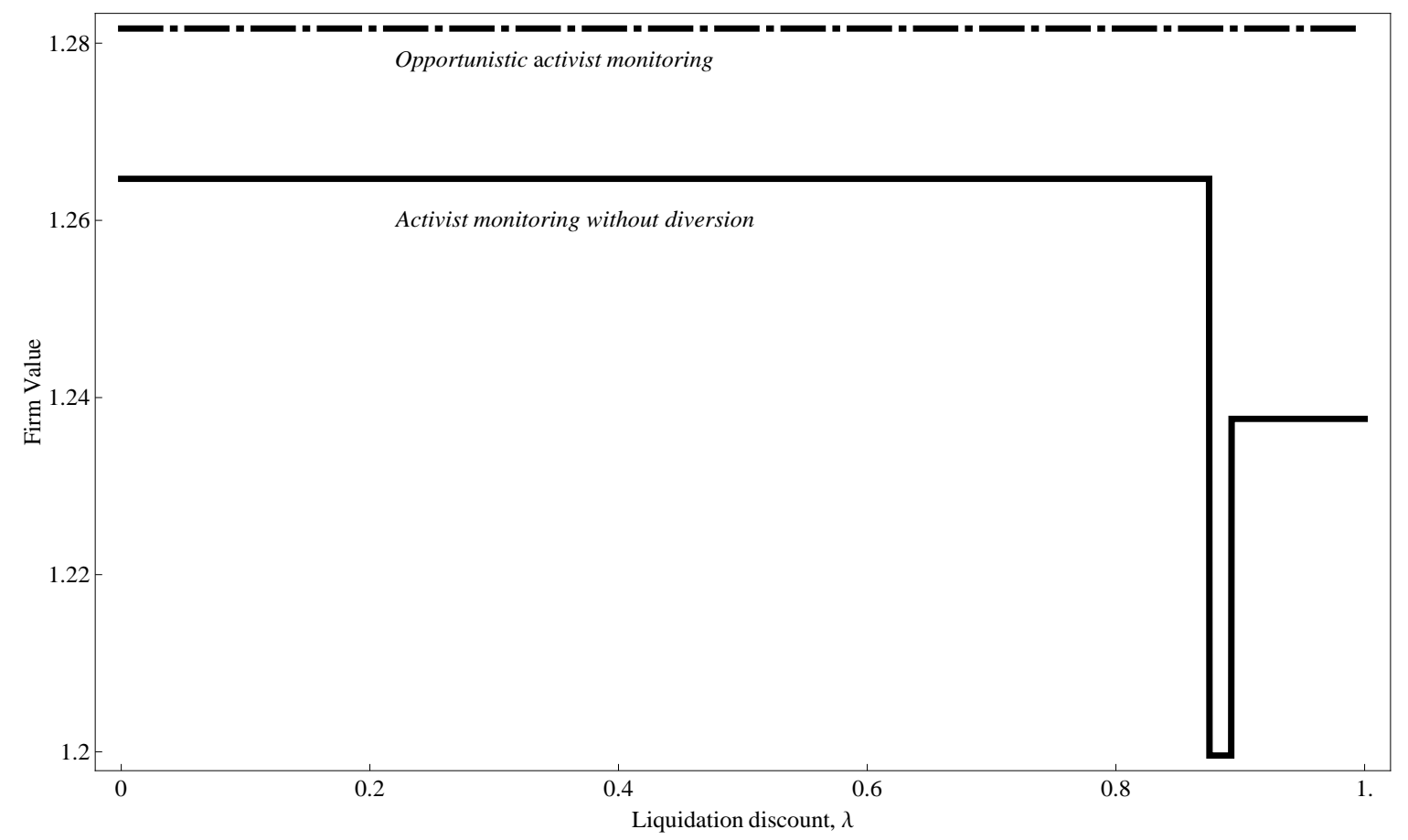

Figure 6: Investor monitoring with and without activist diversion as a function of asset liquidity

In this figure, we compare investor monitoring with multiple opportunistic activists, and that with investor monitoring, featuring either a single activist, or purely passive investors. Monitoring by multiple opportunistic activists dominates every equilibrium with investor monitoring without opportunism. The reason is that there is very little dissipation here. The two opportunistic activists monitor enough in random fashion to successfully deter stealing. 


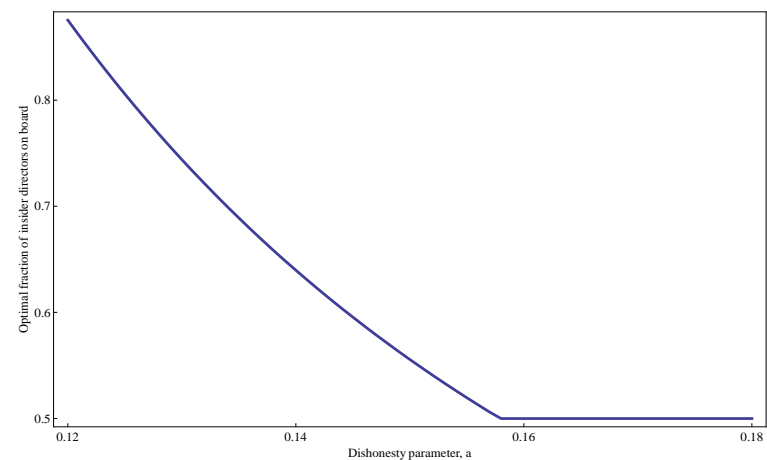

Figure 7: Fraction of insider directors vs. honesty

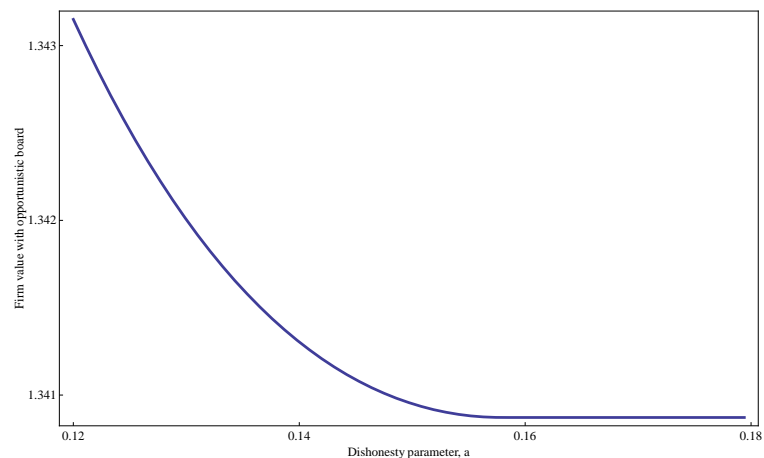

Figure 8: Firm value with opportunistic board vs. honesty

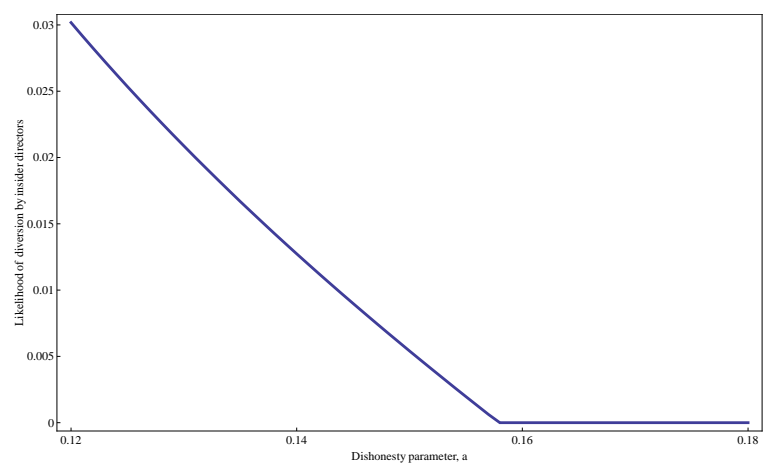

Figure 9: Likelihood of board stealing vs. honesty 


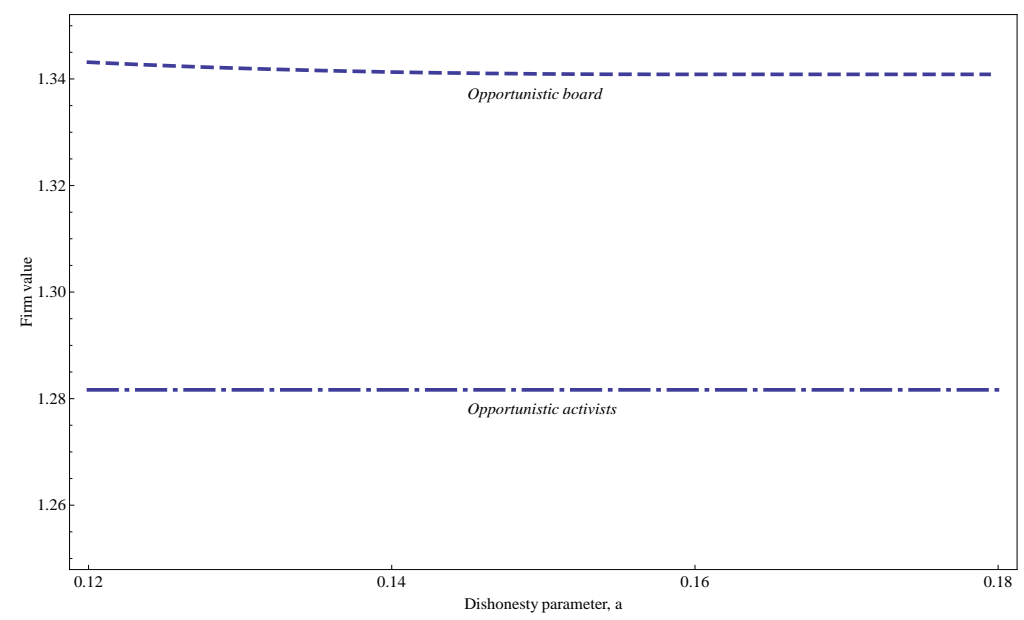

Figure 10: Comparing firm value with opportunistic activists and an opportunistic board

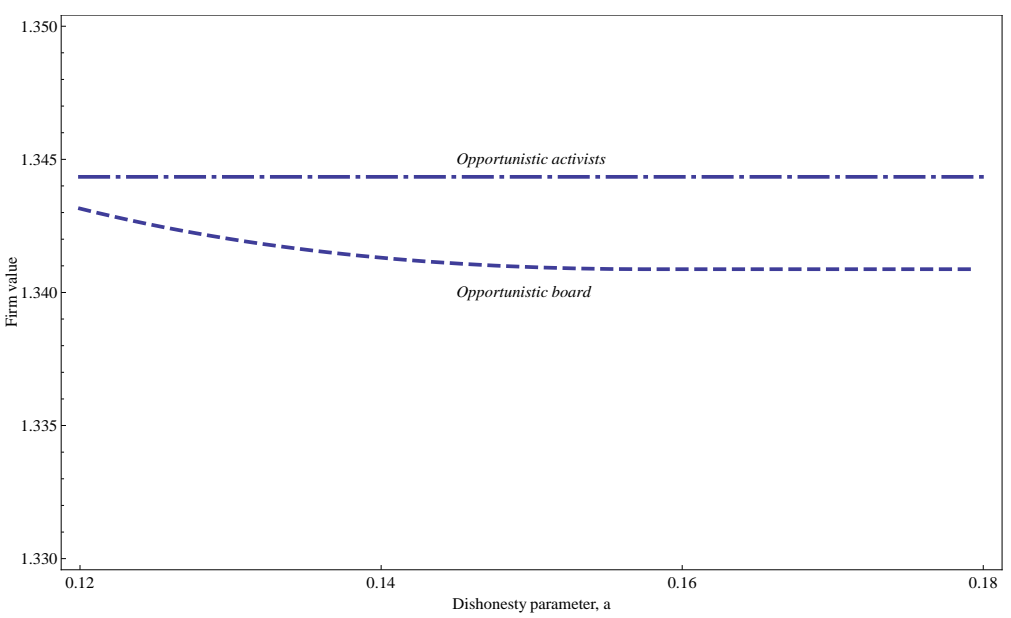

Figure 11: Comparing firm value with opportunistic activists and an opportunistic board

In this set of two figures, we compare firm value under investor monitoring with multiple opportunistic activists with that under monitoring by an opportunistic board. In Figure 11, monitoring by multiple opportunistic activists dominates the opportunistic board across the entire parameter space. The first reason is that the discount rates for activist and passive investors are close to each other $\left(r=0.24, r_{A}=0.2401\right)$, which leads to lower dissipation by diverting activists. The second and more important reason is that money diverted by opportunistic insiders is lost forever, while that diverted by activists finds their way into firm value through security valuation. The contrary case is shown in Figure 10, which has been generated assuming values for all variables identical to those in Figure 11, except the value for $r_{A}$ which has been assumed as 0.28 , compared to a value of 0.24 for $r$. 